\title{
Supported ionic liquids as efficient materials to remove non- steroidal anti-inflammatory drugs from aqueous media
}

Hugo F. D. Almeida ${ }^{\mathrm{a}, \mathrm{b}, \S}$, Márcia C. Neves ${ }^{\mathrm{b}, ~}$, Tito Trindade ${ }^{\mathrm{b}}$, Isabel M. Marrucho ${ }^{\mathrm{a}, \mathrm{c}}$ and Mara G. Freire ${ }^{b^{*}}$

anstituto de Tecnologia Química e Biológica António Xavier, Universidade Nova de Lisboa, 2780-157 Oeiras, Portugal

${ }^{\mathrm{b}}$ CICECO - Aveiro Institute of Materials, Chemistry Department, University of Aveiro, 3810-193 Aveiro, Portugal

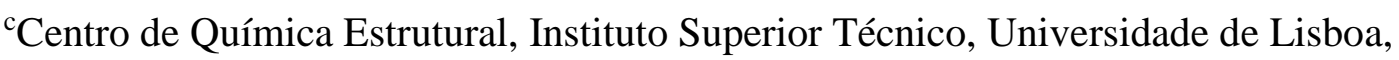
Avenida Rovisco Pais, 1049-001 Lisboa, Portugal.

${ }^{\S}$ These authors contributed equally.

*Corresponding author

Tel: +351-234-370200; Fax: +351-234-370084; E-mail address: maragfreire@ua.pt 


\section{Abstract}

Non-steroidal anti-inflammatory drugs (NSAIDs) are largely consumed worldwide. As a result, NSAIDs were already found in a variety of environmental aqueous samples, in concentrations ranging from $\mathrm{ng} / \mathrm{L}$ to $\mu \mathrm{g} / \mathrm{L}$. This is due to the inability of the currently used technologies in sewage treatment plants (STPs) and wastewater treatment plants (WWTPs) to completely remove such pollutants/contaminants, thus leading to serious environmental and public health concerns. This work addresses the preparation and application of materials based on silica chemically modified with ionic liquids (SILs) as alternative adsorbents to remove NSAIDs from aqueous media. Modified silica-based materials comprising the 1-methyl-3-propylimidazolium cation combined with six anions were prepared, and chemically and morphologically characterized. Adsorption kinetics, diffusion models and isotherms of sodium diclofenac - as one of the most worldwide consumed NSAIDs - were determined at 298 K. The Boyd's film diffusion and Webber's pore diffusion models were used to disclose the rate controlling step affecting the adsorption process. A maximum equilibrium concentration of sodium diclofenac of 0.74 mmol $(0.235 \mathrm{~g})$ per $\mathrm{g}$ of adsorbent was obtained. Several solvents were tested to remove diclofenac and to regenerate SILs, being the mixture composed of 1-butanol and water (85:15, v:v) identified as the most promising and eco-friendly. After 3 regeneration steps, the material is able to keep up to $75 \%$ of its initial adsorption efficiency. Considering the maximum values reported for sodium diclofenac in effluents from WWTPs/STPs, $1 \mathrm{~g}$ of the most efficient material is "ideally" able to treat ca. 50,000 L of water. These materials can thus be envisioned as efficient filters to be implemented at domestic environment in countries where the levels of pharmaceuticals are particularly high in drinking water.

Keywords: Supported Ionic Liquid, Adsorption, Isotherm, Kinetics, Sodium diclofenac. 


\section{Introduction}

Due to the large worldwide consumption of active pharmaceutical ingredients (APIs), their global occurrence in the environment is a current matter of remarkable concern [1]. APIs have been found in non-negligible levels (up to $\mu \mathrm{g} . \mathrm{L}^{-1}$ ) in sewage treatment plants (STPs), wastewater treatment plants (WWTPs) and surface water effluents [2,3], leading to serious problems in environmental and public health after long-term exposure [4]. Although the main purpose of pharmaceuticals is to improve humans and animals health, when released into the environment they will affect the entire biota, from primary producers and consumers to top predators [4,5]. Most of these compounds are cytotoxic, genotoxic and/or endocrine disruptors. Since the administered doses of APIs are not completely metabolized by humans or animals, they are excreted in the urine in either conjugated or in unchanged forms, reaching the aquatic environment [6]. Also, unnecessary or expired medications are recurrently disposed (directly) into wastewaters [7]. Albeit WWTPs use advanced processes for water purification, such as membrane filtration, ozonation, chlorination, flocculation/sedimentation and adsorption, none of these strategies was specifically designed to remove APIs [8], explaining why some of these contaminants were already detected even in drinking water $[9,10]$. According to the Global Water Research Coalition (GWRC) criteria [11] some non-steroidal antiinflammatory drugs (NSAIDs) are part of the top 10 persistent pollutants list, where diclofenac is the most prevalent NSAID used throughout the world [12]. As with most of APIs, the degradation of diclofenac is limited [13] and there is a lack of efficient strategies for its removal from aqueous samples [14]. Accordingly, diclofenac has been detected in rivers, sediments and sludges [10]; more recently, it has been found in drinking water sources [15]. 
Research works aiming the removal of diclofenac from aqueous samples and the development of alternative treatment strategies which could be implemented in WWTPs have been previously carried out, where materials such as MOFs (metal organic frameworks) [16-18], activated carbon [19,20] and silica [21] have been studied. Removal efficiencies of diclofenac of ca. 93\% were achieved by Betrán et al. [22], using ozone and activated carbon. Primary treatments with coagulating and flocculating agents, such as $\mathrm{FeCl}_{3}$ and $\mathrm{Al}_{2}\left(\mathrm{SO}_{4}\right)_{3}$, have also been reported; yet, these processes are not able to completely remove the drug from wastewater samples (maximum removal of 70\%) [23]. Furthermore, conventional activated sludge processes showed a higher efficiency when compared to membrane bioreactors, where a $30-70 \%$ of removal of diclofenac was obtained [24].

Although advances have been accomplished in the past years, the development of costefficient techniques able to completely remove diclofenac and other APIs from the aquatic environment is still an urgent requirement of a sustainable modern society. To this end, supported ionic liquids (SILs) can be seen as an alternative class of materials to be employed in removal/adsorption processes. Several SILs, where the IL is covalently attached to the support material, have been reported in the literature to separate inorganic and organic anions, as well as organic compounds [25-27]. In addition to these, Myasoedova et al. [28] and Li et al. [29] reported the use of physically immobilized ILs, i.e. supported ionic liquid phases (SILPs), to extract $\mathrm{Pt}(\mathrm{IV})$ and $\mathrm{Pu}(\mathrm{IV})$, and five phthalates, respectively, from environmental water samples. Furthermore, an hybrid material composed of poly-[N,N-dimethyl-dodecyl-(4-vinylbenzyl)ammonium chloride] and polyoxometalate (PIL/POM) was successfully applied in the separation of ionic dyes [30]. Despite aqueous samples, SILPs comprising physically immobilized ILs have been investigated in the separation of gases [30-32]. Supported ionic liquid membranes have 
also been investigated for separation purposes [33]. All these materials have shown to be promising in a variety of separations due to their chemical functionalization or impregnation with ILs. The presence of ILs in solid phases allows the preparation of materials bearing some properties of ILs, particularly the tunable properties provided by the IL cation/anion chemical structure design. In fact, it is mainly due to their designer solvents feature that ILs have been successfully applied in a variety of fields [31-35].

The combination of the ILs properties [36] with the advantages of solid supports raised the attention on the use of SILs as alternative materials for solid-phase extraction (SPE) [37]. To the best of our knowledge, the use of SILs as adsorbents for the removal of APIs from aqueous media has not been previously reported. In this work, IL-functionalized silica was prepared by chemically bonding 3 -chloropropyltrimethoxysilane onto the silica surface, followed by reaction with N-methylimidazolium, resulting in the formation of 1methyl-3-propylimidazolium-based supported silica with chloride as the counter ion $\left([\mathrm{Si}]\left[\mathrm{C}_{3} \mathrm{C}_{1} \mathrm{im}\right] \mathrm{Cl}\right)$. Five additional SILs were prepared from $[\mathrm{Si}]\left[\mathrm{C}_{3} \mathrm{C}_{1} \mathrm{im}\right] \mathrm{Cl}$ by anion exchange, namely $[\mathrm{Si}]\left[\mathrm{C}_{3} \mathrm{C}_{1} \mathrm{im}\right][\mathrm{SCN}], \quad[\mathrm{Si}]\left[\mathrm{C}_{3} \mathrm{C}_{1} \mathrm{im}\right]\left[\mathrm{N}(\mathrm{CN})_{2}\right], \quad[\mathrm{Si}]\left[\mathrm{C}_{3} \mathrm{C}_{1} \mathrm{im}\right][\mathrm{Tos}]$, $[\mathrm{Si}]\left[\mathrm{C}_{3} \mathrm{C}_{1} \mathrm{im}\right][\mathrm{Male}]$ and $[\mathrm{Si}]\left[\mathrm{C}_{3} \mathrm{C}_{1} \mathrm{im}\right]\left[\mathrm{NTf}_{2}\right]$ - their full description is given below. Silica-based SILs were chosen since silica is a low-cost and inert material, easily chemically modified, and has a high specific surface area, mechanical strength and thermal stability. All SILs were chemically and morphologically characterized and evaluated as alternative adsorbents to remove sodium diclofenac from aqueous media since it is the most prevalent NSAID used throughout the world, thus recurrently found in aqueous streams and even in drinking water [38]. Adsorption kinetics, diffusion models and isotherms of the drug were determined at $298 \mathrm{~K}$, allowing to infer the materials removal/adsorption performance and diffusion mechanism for APIs. Water and several 
alcohols and their mixtures were investigated to remove sodium diclofenac and to regenerate SILs.

\section{Experimental}

\subsection{Materials}

The non-steroidal anti-inflammatory drug, sodium diclofenac (CAS\# 15307-79-6), was acquired from Sigma-Aldrich. The physicochemical properties of sodium diclofenac are listed in Table SI1 in the Supplementary Material. For the SILs preparations, silica gel

(60 $\AA, 0.2-0.5 \mathrm{~mm})$, used as the supporting material, was acquired from Merck. The solvents used to prepare the IL-functionalized silica, $\left([\mathrm{Si}]\left[\mathrm{C}_{3} \mathrm{C}_{1} \mathrm{im}\right] \mathrm{Cl}\right)$, were hydrochloric acid (CAS\# 7647-01-0, purity $37 \%$ ) and toluene (CAS\# 108-88-3, purity $99.8 \%$ ), both acquired from Sigma Aldrich, ethanol (CAS\# 64-17-5, purity $99.9 \%$ ) from Carlo Erba, methanol (CAS\# 67-56-1, HPLC grade) from Chem-Lab, and (3chloropropyl)trimethoxysilane (CAS\# 2530-87-2, purity $98 \%$ ) and Nmethylimidazolium (CAS\# 616-47-7, purity $99 \%$ ) from Acros Organics. To obtain the remaining SILs by anion exchange, NaSCN (CAS\# 540-72-7, purity $98 \%$ ) from SigmaAldrich, $\mathrm{NaN}(\mathrm{CN})_{2}$ (CAS\# 1934-75-4, purity $96 \%$ ) from Alfa Aesar, NaTos (sodium tosylate, CAS\# 657-84-1, purity > $90 \%$ ) from Alfa Aesar, $\mathrm{NaC}_{4} \mathrm{H}_{3} \mathrm{O}_{4}$ (sodium malenate, CAS\# 3105-55-3, purity $99 \%$ ) from Sigma-Aldrich, and LiNTf 2 (CAS\# 90076-65-6, purity $99 \%$ ) from Iolitec were used. The water used in the adsorption experiments was double distilled, passed across a reverse osmosis system and further treated with a MilliQ plus 185 water purification equipment. For the desorption and SILs regeneration assays, methanol (CAS\# 67-56-1, HPLC grade) from Chem-Lab, ethanol (CAS\# 64-175, purity $99.9 \%$ ) from Carlo Erba, 1-butanol (CAS\# 71-36-3, >99.5\%) and 2-butanol (CAS\# 78-92-2, purity 99\%) from Acros Organics, and sodium chloride (CAS\# 7647-14- 
5, purity 99.5\%) and hydrochloric acid (CAS\# 7647-01-0, purity $37 \%$ ) from Panreac, were used.

\subsection{Synthesis of IL-functionalized silica materials}

The chloride-based functionalized silica, $[\mathrm{Si}]\left[\mathrm{C}_{3} \mathrm{C}_{1} \mathrm{im}\right] \mathrm{Cl}$, was prepared by the treatment of chloropropyl silanized silica $\left([\mathrm{Si}]\left[\mathrm{C}_{3}\right] \mathrm{Cl}\right)$ with an excess of $\mathrm{N}$-methylimidazole in anhydrous toluene according to the literature [26], with some optimizations carried out by us described as follows. Silica was first immersed in hydrochloric acid (37\%) for $24 \mathrm{~h}$, and then washed with double distilled water and dried under vacuum for $24 \mathrm{~h}$ at $378 \mathrm{~K}$. This activated silica $(5.0 \mathrm{~g})$ was re-suspended in $60 \mathrm{~mL}$ of dried toluene, followed by the addition of $5.0 \mathrm{~mL}$ of 3-chloropropyltrimethoxysilane, and $0.5 \mathrm{~mL}$ of triethylamine (used as catalyst). This suspension was magnetically stirred and refluxed at ca. $366 \mathrm{~K}$ for $24 \mathrm{~h}$. After refluxing, the reaction was stopped and cooled down to room temperature, transferred to a vacuum glass filter, and washed with toluene $(100 \mathrm{~mL})$, ethanol-water $(1: 1, \mathrm{v}: \mathrm{v})$ mixture $(200 \mathrm{~mL})$, double distilled water $(500 \mathrm{~mL})$, and finally with methanol $(100 \mathrm{~mL})$. The chloropropyl silica obtained, $[\mathrm{Si}]\left[\mathrm{C}_{3}\right] \mathrm{Cl}$, was dried under vacuum at 333 $\mathrm{K}$ for $24 \mathrm{~h}$, before the reaction with $\mathrm{N}$-methylimidazole. To this end, $5.0 \mathrm{~g}$ of dried chloropropyl silica was placed in a reaction vial containing $60 \mathrm{~mL}$ of toluene and $5.0 \mathrm{~mL}$ of N-methylimidazole. The mixture was refluxed at ca. $380 \mathrm{~K}$ under stirring for $24 \mathrm{~h}$. The reaction was stopped, and the modified silica was cooled down to room temperature, transferred to a vacuum glass filter, and washed with methanol $(350 \mathrm{~mL})$, water $(300 \mathrm{~mL})$, and again with methanol $(150 \mathrm{~mL})$. The chemically modified silica, $[\mathrm{Si}]\left[\mathrm{C}_{3} \mathrm{C}_{1} \mathrm{im}\right] \mathrm{Cl}$, was dried under vacuum at $323 \mathrm{~K}$ for $8 \mathrm{~h}$ prior to their characterization and determination of the kinetic and adsorption isotherms. Fig. 1 shows a schematic diagram of the synthesis route used for the preparation of $[\mathrm{Si}]\left[\mathrm{C}_{3} \mathrm{C}_{1} \mathrm{im}\right] \mathrm{Cl}$. 


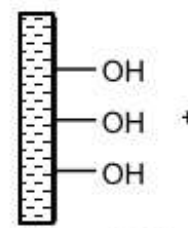

Activated Silica

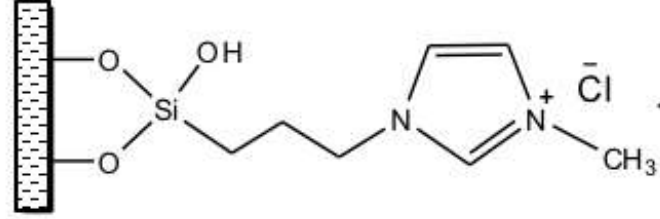

$[\mathrm{Si}]\left[\mathrm{C}_{3} \mathrm{C}_{1} \mathrm{im}\right] \mathrm{Cl}$

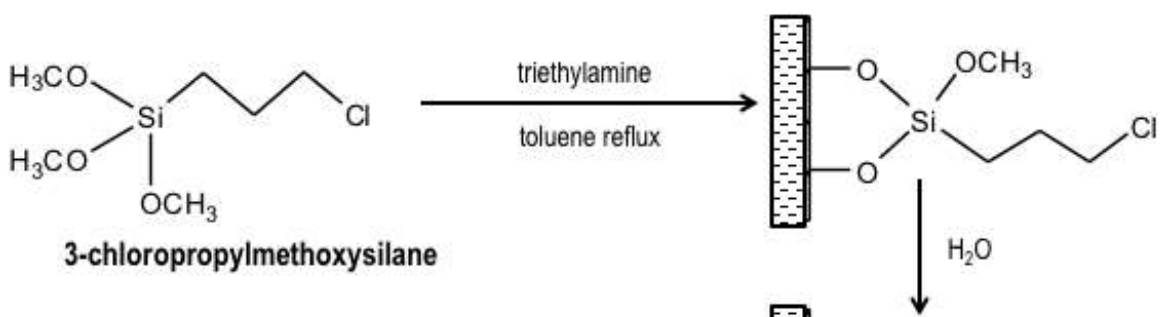

$\mathrm{N}$-methylimidazolium

toluene reflux

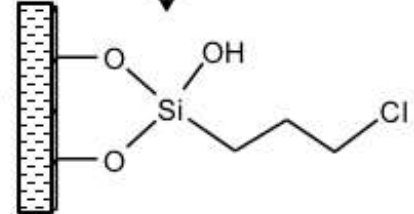

$[\mathrm{Si}]\left[\mathrm{C}_{3}\right] \mathrm{Cl}$

Fig. 1. Synthesis route to prepare $[\mathrm{Si}]\left[\mathrm{C}_{3} \mathrm{C}_{1} \mathrm{im}\right] \mathrm{Cl}$.

$[\mathrm{Si}]\left[\mathrm{C}_{3} \mathrm{C}_{1} \mathrm{im}\right][\mathrm{SCN}],[\mathrm{Si}]\left[\mathrm{C}_{3} \mathrm{C}_{1} \mathrm{im}\right]\left[\mathrm{N}(\mathrm{CN})_{2}\right],[\mathrm{Si}]\left[\mathrm{C}_{3} \mathrm{C}_{1} \mathrm{im}\right][\mathrm{Tos}],[\mathrm{Si}]\left[\mathrm{C}_{3} \mathrm{C}_{1} \mathrm{im}\right][\mathrm{Male}]$ and $[\mathrm{Si}]\left[\mathrm{C}_{3} \mathrm{C}_{1} \mathrm{im}\right][\mathrm{NTf} 2]$ were prepared by anion exchange from $[\mathrm{Si}]\left[\mathrm{C} 3 \mathrm{C}_{1} \mathrm{im}\right] \mathrm{Cl}$ - cf. Fig. 2. These anions were chosen to explore the effect of the counter ion on the materials removal performance. $0.5 \mathrm{~g}$ of [ $\mathrm{Si}]\left[\mathrm{C}_{3} \mathrm{C}_{1} \mathrm{im}\right] \mathrm{Cl}$ was mixed with $0.5 \mathrm{~g}$ (anion in excess) of $\mathrm{NaSCN}$, $\mathrm{NaN}(\mathrm{CN})_{2}, \mathrm{NaTos}, \mathrm{NaC}_{4} \mathrm{H}_{3} \mathrm{O}_{4}$ or $\mathrm{LiNTf}_{2}$, in $40 \mathrm{~mL}$ of double distilled water, and left under moderate stirring and temperature for $24 \mathrm{~h}$. The materials were then filtered and washed with double distilled water. The functionalized silica was dried under vacuum at $323 \mathrm{~K}$ for $8 \mathrm{~h}$ prior to its characterization and use. Fig. 2 depicts a schematic diagram of the approach used to prepare $[\mathrm{Si}]\left[\mathrm{C}_{3} \mathrm{C}_{1} \mathrm{im}\right][\mathrm{SCN}], \quad[\mathrm{Si}]\left[\mathrm{C}_{3} \mathrm{C}_{1} \mathrm{im}\right]\left[\mathrm{N}(\mathrm{CN})_{2}\right]$, $[\mathrm{Si}]\left[\mathrm{C}_{3} \mathrm{C}_{1} \mathrm{im}\right][\mathrm{Tos}],[\mathrm{Si}]\left[\mathrm{C}_{3} \mathrm{C}_{1} \mathrm{im}\right][\mathrm{Male}]$ and $[\mathrm{Si}]\left[\mathrm{C}_{3} \mathrm{C}_{1} \mathrm{im}\right]\left[\mathrm{NTf}_{2}\right]$, as well as the respective chemical structures. 

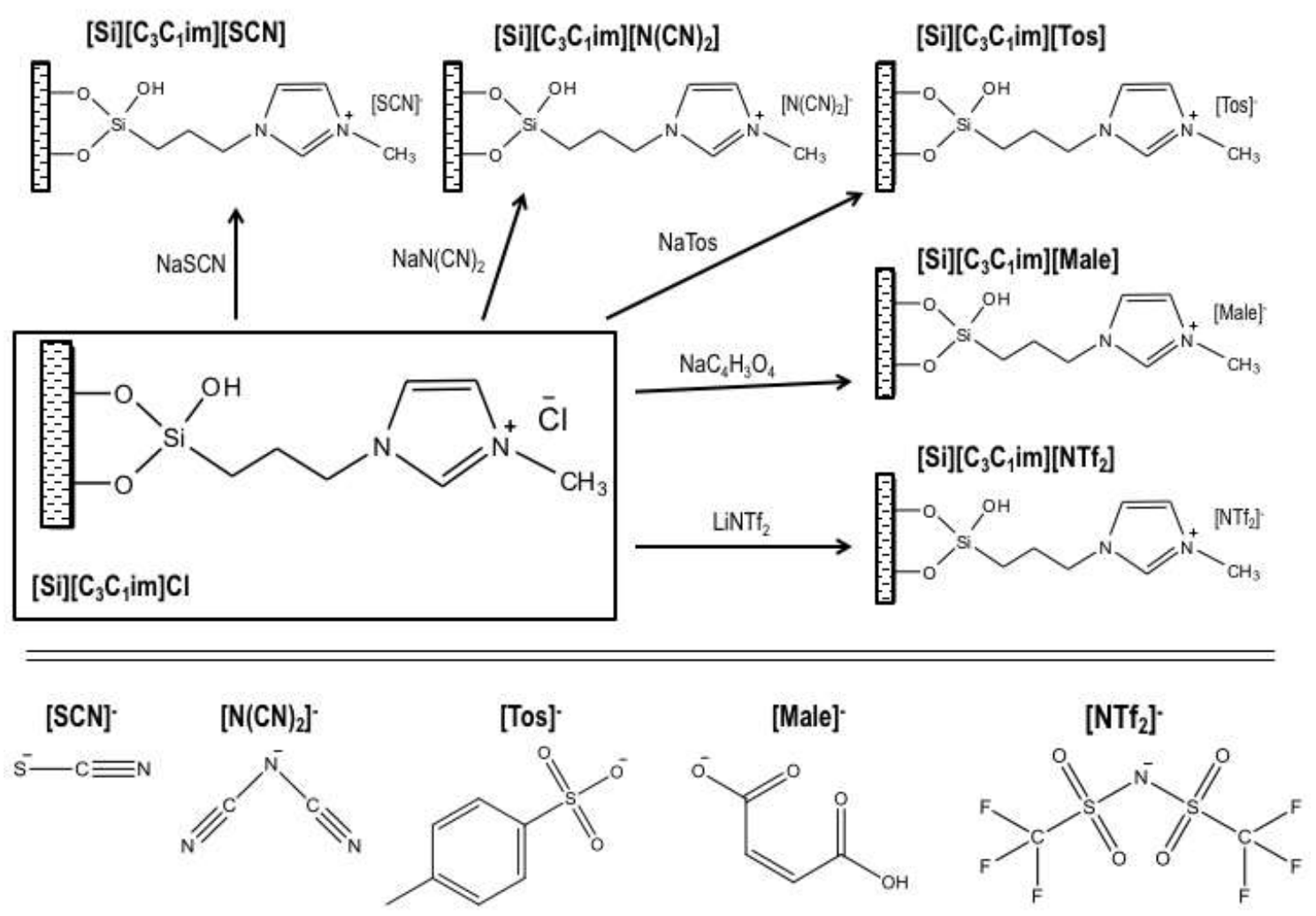

Fig. 2. Preparation of supported IL materials with thiocyanate $\left([\mathrm{SCN}]^{-}\right)$, dicyanamide $\left(\left[\mathrm{N}(\mathrm{CN})_{2}\right]^{-}\right)$, tosylate $\left([\mathrm{Tos}]^{-}\right), 3$-carboxy-2-hydroxypropanoate (malenate, [Male $\left.]^{-}\right)$and bis(trifluoromethylsulfonyl)imide $\left(\left[\mathrm{NTf}_{2}\right]^{-}\right)$anions.

\subsection{Materials characterization}

Fourier transform infrared (FTIR) spectra of activated silica, $[\mathrm{Si}]\left[\mathrm{C}_{3}\right] \mathrm{Cl}$, and $[\mathrm{Si}]\left[\mathrm{C}_{3} \mathrm{C}_{1} \mathrm{im}\right] \mathrm{Cl}$ were acquired using a Perkin Elmer BX Spectrometer, with a resolution of $5 \mathrm{~cm}^{-1}$ and equipped with a horizontal Golden Gate ATR cell, in the range of 4000-500 $\mathrm{cm}^{-1}$. Solid state ${ }^{13} \mathrm{C}$ NMR spectra were recorded at $9.7 \mathrm{~T}$ on a Bruker Avance III - 400 MHz spectrometer (DSX model) using $4 \mathrm{~mm}$ BL cross-polarization magic angle spinning (CPMAS) VTN probes at $100.6 \mathrm{MHz}$, at room temperature. In order to increase the signal-to-noise ratio of the solid-state spectra, the CPMAS NMR ${ }^{13} \mathrm{C}$ settings used were 
the following: $v_{1}^{13} \mathrm{C}=55 \mathrm{kHz}$; recycle delay, $4 \mathrm{~s}$; contact time, $1-2 \mathrm{~ms} ; \mathrm{NS}=1 \mathrm{k} ; v_{\mathrm{R}}=$ $12 \mathrm{kHz}$. SPINAL-64 decoupling was used during data acquisition.

Carbon, hydrogen, nitrogen and sulfur contents (in weight percentage) of [ $\mathrm{Si}]\left[\mathrm{C}_{3} \mathrm{C}_{1} \mathrm{im}\right] \mathrm{Cl}$, $[\mathrm{Si}]\left[\mathrm{C}_{3} \mathrm{C}_{1} \mathrm{im}\right][\mathrm{SCN}],[\mathrm{Si}]\left[\mathrm{C}_{3} \mathrm{C}_{1} \mathrm{im}\right]\left[\mathrm{N}(\mathrm{CN})_{2}\right],[\mathrm{Si}]\left[\mathrm{C}_{3} \mathrm{C}_{1} \mathrm{im}\right][\mathrm{Tos}],[\mathrm{Si}]\left[\mathrm{C}_{3} \mathrm{C}_{1} \mathrm{im}\right][\mathrm{Male}]$ and $[\mathrm{Si}]\left[\mathrm{C}_{3} \mathrm{C}_{1} \mathrm{im}\right]\left[\mathrm{NTf}_{2}\right]$ were determined using a TruSpec 630-200-200, with a sample of 2 $\mathrm{mg}$, combustion furnace temperature at $1348 \mathrm{~K}$, afterburner temperature of $1123 \mathrm{~K}$, and detection method of infrared absorption for carbon, hydrogen and sulfur, and thermal conductivity for nitrogen. Scanning electron microscopy (SEM) was performed using a Hitashi SU-70, equipped with EDX Bruker model Quantax 400. Samples were prepared by deposition of an aliquot of a water suspension of the materials on a glass substrate. After evaporation of the solvent, samples were coated by carbon evaporation (Emitech K950X, France).

The specific surface area and pore structure characterization of SILs were determined by nitrogen adsorption at $77 \mathrm{~K}$ using a surface area analyser Micromeritics Gemini V-2380. The samples were degassed overnight at $373 \mathrm{~K}$ before these measurements. The surface area $\left(\mathrm{S}_{\mathrm{BET}}\right)$ of silica, of $[\mathrm{Si}]\left[\mathrm{C}_{3}\right] \mathrm{Cl}$ and of the prepared SILs was estimated by the BET (Brunaver-Emmett-Teller) method, the pore surface area (A) and pore volume (V) were determined by the BJH (Barrett-Joyner-Halenda) model, and the mean pore diameter $\left(\mathrm{D}_{\mathrm{p}}\right)$ was calculated from $\left.D_{p}=(4 V) / A\right)$. Zeta potential measurements were performed with a Zeta Sizer Nano Series (Malvern), using $\mathrm{HCl}$ and $\mathrm{NaOH}$ aqueous solutions (0.1 M) for $\mathrm{pH}$ adjustments.

\subsection{Adsorption kinetics, isotherms and particles diffusion}

The adsorption kinetics and isotherms of the six SILs were determined using aqueous solutions of sodium diclofenac, as a major representative of the NSAIDs class. For the 
adsorption kinetics, a solution of sodium diclofenac with a concentration of 0.079 mmol.L $\mathrm{L}^{-1}$ was used, while for the adsorption isotherms, concentrations of the drug ranging from 0.003 to $1.446 \mathrm{mmol} . \mathrm{L}^{-1}$ were employed. In these experiments, $2.5 \mathrm{mg}$ of each SIL were mixed with $10 \mathrm{~mL}$ of sodium diclofenac aqueous solutions in $50 \mathrm{~mL}$ pyrex Erlenmeyers, and then placed in an orbital shaker at $120 \mathrm{rpm}$ and $(298.2 \pm 0.5) \mathrm{K}$. For the adsorption kinetics evaluation, samples were taken from 0 to $180 \mathrm{~min}$, while for the adsorption isotherms evaluation samples were taken at $120 \mathrm{~min}$. All samples were centrifuged at $5000 \mathrm{rpm}$ for $5 \mathrm{~min}$, and the amount of sodium diclofenac in the water phase was quantified through UV-spectroscopy, using a Shimadzu UV-1800, PharmaSpec UV-Vis Spectrophotometer, at a wavelength of $276 \mathrm{~nm}$. At least, three replicates were investigated for each condition.

The equilibrium concentration of adsorbate in the solid phase $\left(q_{e} / \mathrm{mmol}^{-1}\right)^{-1}$ was determined according to Eq. 1:

$q_{e}=\left(\frac{\left(C_{0}-C_{e}\right) \times V}{w}\right)$

where $w$ is the weight of each SIL $(\mathrm{g}), V$ is the volume of the sodium diclofenac aqueous solution (L), $C_{0}$ is the initial concentration of sodium diclofenac in solution and $C_{e}$ is the equilibrium concentration of sodium diclofenac after adsorption onto SILs (mmol.L $\mathrm{L}^{-1}$ ). Both pseudo first-order and pseudo second-order models were applied to correlate the experimental data, namely with the linear form of the Lagergren's [39] first order rate equation (Eq. 2) and Ho's [40] second order rate equation (Eq. 3):

$\ln \left(q_{e}-q_{t}\right)=\ln q_{e}-k_{1} t$

$\frac{t}{q_{t}}=\frac{1}{k_{2} q_{e}^{2}}+\frac{1}{q_{e}}$

where $t$ is the time (min), $q_{e}$ is the amount of sodium diclofenac adsorbed onto the adsorbent at equilibrium (mmol. $\left.\mathrm{g}^{-1}\right), q_{t}$ is the amount of sodium diclofenac adsorbed onto the adsorbent at different times $\left(\mathrm{mmol} \cdot \mathrm{g}^{-1}\right), k_{1}\left(\mathrm{~min}^{-1}\right)$ is the rate constant of the pseudo 
first-order adsorption, and $k_{2}\left(\mathrm{gmmol}^{-1} \mathrm{~min}^{-1}\right)$ is the rate constant of the pseudo-secondorder adsorption.

The diffusion process can be controlled by one or combined steps: film diffusion, pore diffusion, surface diffusion and sorption in the pore surface. In order to evaluate the rate limiting process, the most common diffusion models, namely the Boyd's film diffusion (Eq. 6 and Eq. 7) and Webber's pore diffusion (Eq. 8) models [43-45], were used:

$$
\begin{aligned}
& B t=-0.4977-\ln (1-F(t)), \text { for } F \text { values }>0.85 \\
& B t=\left(\sqrt{\pi}-\sqrt{\pi-\frac{\pi^{2} F(t)}{3}}\right)^{2}, \text { for } F \text { values }>0.85 \\
& q_{t}=K_{i d} t^{1 / 2}
\end{aligned}
$$

where $F(t)$ is the fractional attainment of equilibrium at different times $t$, in which $F(t)=$ $q_{t} / q_{e}$ and $B t$ is a function of $F(t)$, and $q_{t}$ and $q_{e}$ are the sodium diclofenac concentrations adsorbed onto the adsorbent (mmol. $\mathrm{g}^{-1}$ ) at time $t$ and at equilibrium, respectively. $K_{i d}$ is the internal diffusion rate constant $\left(\mathrm{mmol} \cdot \mathrm{g}^{-1} \cdot \mathrm{min}^{1 / 2}\right)$.

The experimental isotherms were fitted with the Langmuir [41] (Eq. 7) and Freundlich [42] (Eq. 8) models:

$$
\begin{aligned}
& q_{e}=\frac{q_{\max } \times B \times C_{e}}{1+B \times C_{e}} \\
& \ln q_{e}=\ln K_{f}+\frac{1}{n} \ln C_{e}
\end{aligned}
$$

where $C_{e}$ is the equilibrium concentration of adsorbate $\left(\mathrm{mmol} . \mathrm{L}^{-1}\right), q_{e}$ is the equilibrium concentration of adsorbate in the solid phase $\left(\mathrm{mmol} \cdot \mathrm{g}^{-1}\right), B\left(\mathrm{~L}_{\mathrm{mmol}}{ }^{-1}\right)$ is the Langmuir isotherm constant, $q_{\max }\left(\mathrm{mmol} \cdot \mathrm{g}^{-1}\right)$ is the maximum monolayer coverage capacity, and $K_{f}$ (adsorption capacity; mmol. $\mathrm{g}^{-1}$ ) and $n$ (adsorption intensity) are the constants of the Freundlich equation. The fitting of the data was performed with SigmaPlot@. 


\subsection{Desorption and regeneration studies}

Envisioning the materials regeneration, desorption studies were performed for the material with higher adsorption capacity for sodium diclofenac, namely [Si][ $\left.\mathrm{C}_{3} \mathrm{C}_{1} \mathrm{im}\right] \mathrm{Cl}$. $50 \mathrm{mg}$ of $[\mathrm{Si}]\left[\mathrm{C}_{3} \mathrm{C}_{1} \mathrm{im}\right] \mathrm{Cl}$ were saturated after contact with $10 \mathrm{~mL}$ of a solution containing 3.929 mmol. $\mathrm{L}^{-1}$ of sodium diclofenac for $24 \mathrm{~h}$, in an orbital shaker at $120 \mathrm{rpm}$ and 298.2 $( \pm 0.5) \mathrm{K}$. The solid was isolated by centrifugation and re-dispersed in several solvents, namely water, methanol, ethanol, 1-butanol, 1-butanol:water mixtures (85:15, v:v), 2butanol, and 2-butanol:water mixtures (85:15, v:v). Water-alcohol mixtures were chosen according to the improved solubility of sodium diclofenac reported by Saei et al. [46], where co-solvency effects are frequently observed in the enhancement of the pharmaceuticals solubility. The SIL was again isolated by centrifugation and the content of sodium diclofenac solutions in each solvent was analysed by UV-Vis spectroscopy, using a Shimadzu UV-1800, Pharma-Spec UV-Vis Spectrophotometer, at a wavelength of $276 \mathrm{~nm}$, using calibration curves established in each solvent. Three replicates were investigated for each solvent. It should be remarked that the adsorption and desorption steps of diclofenac were monitored by UV-Vis spectroscopy, acquiring the full spectra between 190-900 $\mathrm{nm}$. Comparing the absorption spectra of the solutions after being in contact with the SIL and those used for the calibration curves, no changes were observed in the curves profile, thus supporting the drug stability.

The percentage desorption efficiency was calculated using Eq. 9, where $n_{a d s}$ is the adsorbed amount of diclofenac (mmol) and $n_{\text {des }}$ is the desorbed amount of diclofenac (mmol), which are determined by Eq. 10 and Eq. 11,

$$
\begin{aligned}
& \text { Desorption efficiency }(\%)=\frac{n_{\text {des }}}{n_{a d s}} \times 100 \\
& n_{\text {ads }}=\left(C_{0}-C_{e}\right) \times V_{\text {ads }} \\
& n_{\text {des }}=C_{d e s} \times V_{d e s}
\end{aligned}
$$


where $C_{0}$ is the initial concentration of sodium diclofenac in solution (mmol. $\left.\mathrm{L}^{-1}\right), C_{e}$ is the equilibrium concentration of sodium diclofenac after adsorption $\left(\mathrm{mmol} . \mathrm{L}^{-1}\right), C_{d e s}$ is the concentration of sodium diclofenac in the desorption solvent (mmol.. $\left.\mathrm{L}^{-1}\right)$, and $V_{a d s}$ and $V_{d e s}$ are the volume of the sodium diclofenac aqueous solution and the volume of desorption solvent $(\mathrm{L})$, respectively.

After a preliminary screening on the best solvents for the sodium diclofenac desorption, the mixture composed of 1-butanol:water $(85: 15, \mathrm{v}: \mathrm{v})$ was used in the reusability tests of $[\mathrm{Si}]\left[\mathrm{C}_{3} \mathrm{C}_{1} \mathrm{im}\right] \mathrm{Cl}$ after regeneration. $50 \mathrm{mg}$ of $[\mathrm{Si}]\left[\mathrm{C}_{3} \mathrm{C}_{1} \mathrm{im}\right] \mathrm{Cl}$ were saturated after contact with $10 \mathrm{~mL}$ of an aqueous solution containing $3.929 \mathrm{mmol} . \mathrm{L}^{-1}$ of sodium diclofenac for 2h, in an orbital shaker at $120 \mathrm{rpm}$ and $298.2( \pm 0.5) \mathrm{K}$. The solid was isolated by centrifugation and treated with $8 \mathrm{~mL}$ of $\mathrm{NaCl}(0.5 \mathrm{M})$ and $2 \mathrm{~mL} \mathrm{HCl}(0.5 \mathrm{M})$, followed by centrifugation and re-dispersed in $10 \mathrm{~mL}$ of 1-butanol:water $(85: 15, \mathrm{v}: \mathrm{v})$ for $2 \mathrm{~h}$, in an orbital shaker at $120 \mathrm{rpm}$ and $298.2( \pm 0.5) \mathrm{K}$. The SIL was again isolated by centrifugation and the content of sodium diclofenac solutions was analysed by UV-Vis spectroscopy, using a Shimadzu UV-1800, Pharma-Spec UV-Vis Spectrophotometer, at a wavelength of $276 \mathrm{~nm}$, using calibration curves previous established. Before the recycling tests of the material, the material was washed with $\mathrm{NaCl}(0.5 \mathrm{M})$ aqueous solutions to guarantee the chloride content as counter-ion. The experimental conditions are described in detail in Table SI2 in the Supplementary Material.

\section{Results and discussion}

\subsection{Characterization of the prepared SILs}

In order to confirm the silica functionalization with ILs, FTIR spectra of activated silica, chloropropyl silica and $[\mathrm{Si}]\left[\mathrm{C}_{3} \mathrm{C}_{1} \mathrm{im}\right] \mathrm{Cl}$ were acquired. These spectra are given in Fig. SI1 in the Supplementary Material, in which it is observed the disappearance of the band at 
$960 \mathrm{~cm}^{-1}$ related to the bending vibration mode of $\mathrm{Si}-\mathrm{OH}$ [48], thus indicating the silica functionalization. The successful preparation of $[\mathrm{Si}]\left[\mathrm{C}_{3} \mathrm{C}_{1} \mathrm{im}\right] \mathrm{Cl}$ was further confirmed through ${ }^{13} \mathrm{C}$ solid state NMR, whose spectra are shown in Fig. 3. The signals at 51, 24 and $10 \mathrm{ppm}$ correspond to the three carbon atoms of the imidazolium alkyl chain length (C4, C5, and C6), the peaks ranging from 120-140 ppm correspond to the aromatic carbons of imidazolium ( $\mathrm{C} 3$ and $\mathrm{C} 2$ ), and the signal at $37 \mathrm{ppm}$ corresponds to the carbon of the methyl chain $(\mathrm{C} 1)$.

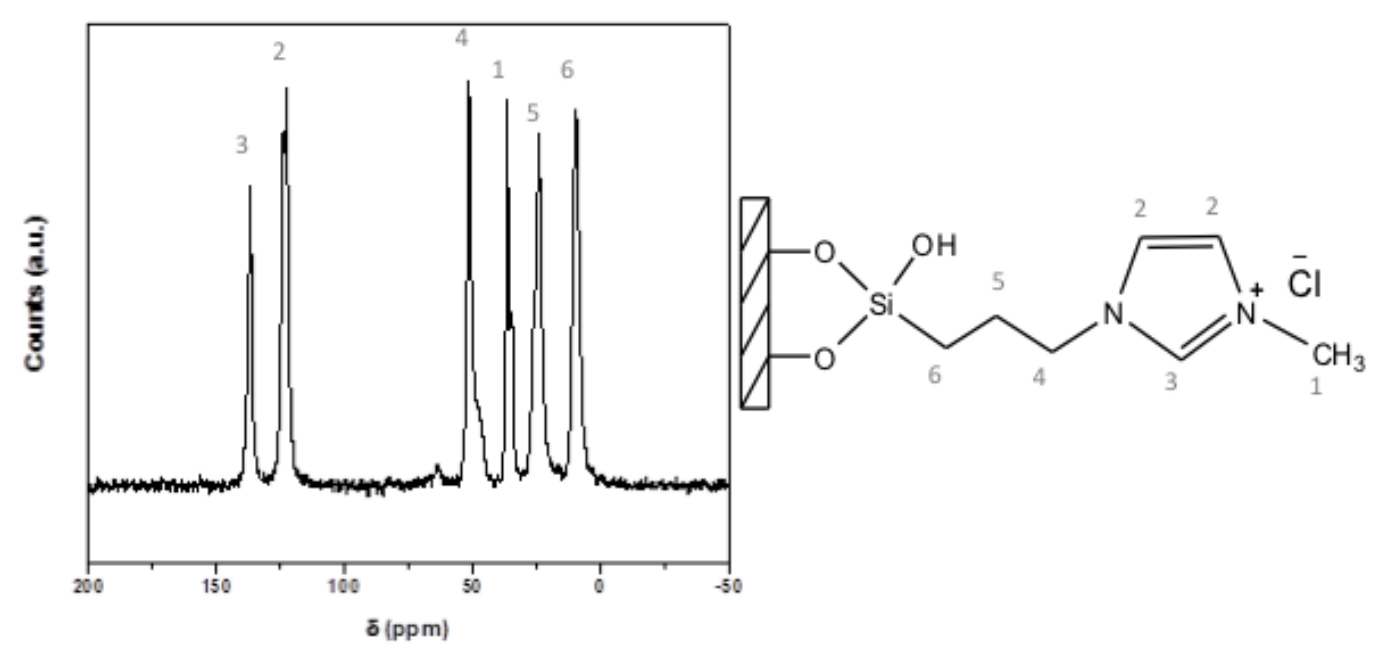

Fig. 3. ${ }^{13} \mathrm{C}$ NMR solid-state spectrum of $[\mathrm{Si}]\left[\mathrm{C}_{3} \mathrm{C}_{1} \mathrm{im}\right] \mathrm{Cl}$.

Fig. 4 depicts the SEM images of activated silica and $[\mathrm{Si}]\left[\mathrm{C}_{3} \mathrm{C}_{1} \mathrm{im}\right] \mathrm{Cl}$, showing that the IL immobilization results in some changes in the surface morphology, in agreement with the conclusions provided by Su et al. [48] on SILs with a different counter ion. The Nimidazolium-based IL material presents a less rough surface, probably due to the presence of the organic moieties at the silica surface. SEM images were also acquired for $[\mathrm{Si}]\left[\mathrm{C}_{3} \mathrm{C}_{1} \mathrm{im}\right][\mathrm{SCN}],[\mathrm{Si}]\left[\mathrm{C}_{3} \mathrm{C}_{1} \mathrm{im}\right]\left[\mathrm{N}(\mathrm{CN})_{2}\right],[\mathrm{Si}]\left[\mathrm{C}_{3} \mathrm{C}_{1} \mathrm{im}\right][\mathrm{Tos}],[\mathrm{Si}]\left[\mathrm{C}_{3} \mathrm{C}_{1} \mathrm{im}\right][\mathrm{Male}]$ and $[\mathrm{Si}]\left[\mathrm{C}_{3} \mathrm{C}_{1} \mathrm{im}\right]\left[\mathrm{NTf}_{2}\right]$ (cf. Fig. SI2 in the Supplementary Material). No significant differences in morphology were observed between the six SILs prepared, although all 
morphologically differ from activated silica. Elemental analysis was additionally carried out to quantitatively determine the carbon, hydrogen, nitrogen, and sulphur contents of the six SILs prepared. The obtained results are provided in Table 1.

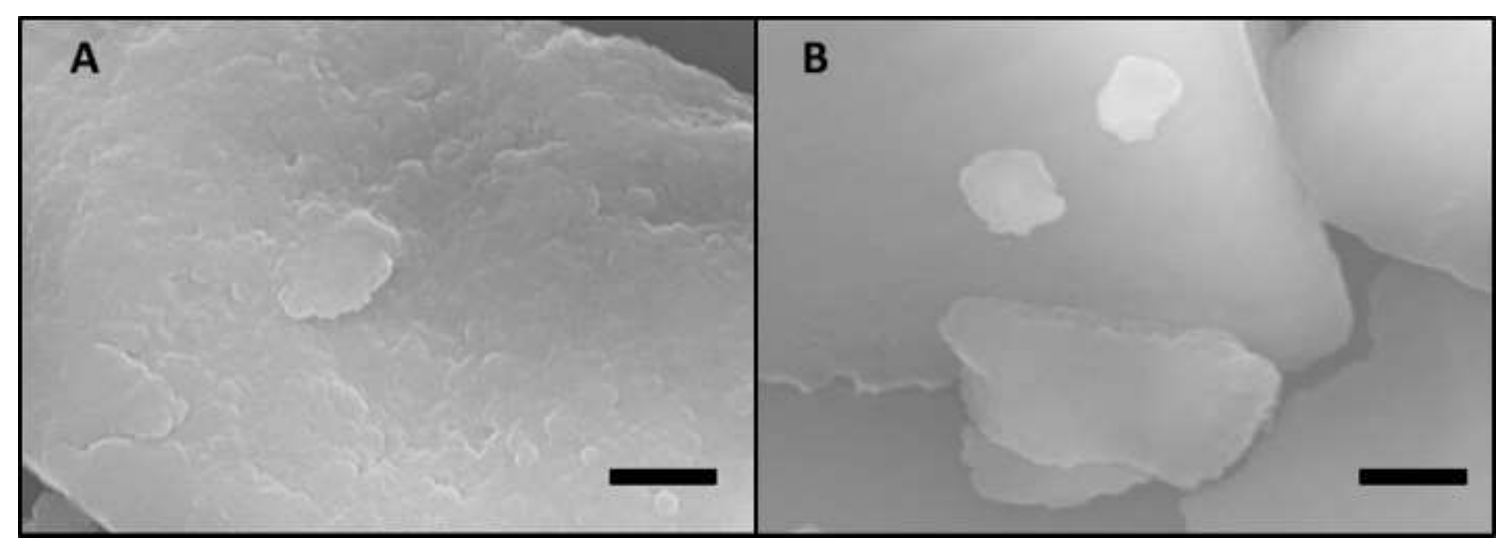

Fig. 4. SEM images of: A) activated silica gel; and $B$ ) $[\mathrm{Si}]\left[\mathrm{C}_{3} \mathrm{C}_{1} \mathrm{im}\right] \mathrm{Cl}$ (the bar corresponds to $0.5 \mu \mathrm{m})$. 
Table 1. Atoms (C, H, N and S) contents and respective standard deviations $(\sigma)$ of activated silica, $[\mathrm{Si}]\left[\mathrm{C}_{3}\right] \mathrm{Cl},[\mathrm{Si}]\left[\mathrm{C}_{3} \mathrm{C}_{1} \mathrm{im}\right] \mathrm{Cl},[\mathrm{Si}]\left[\mathrm{C}_{3} \mathrm{C}_{1} \mathrm{im}\right][\mathrm{SCN}],[\mathrm{Si}]\left[\mathrm{C}_{3} \mathrm{C}_{1} \mathrm{im}\right]\left[\mathrm{N}(\mathrm{CN})_{2}\right]$, $[\mathrm{Si}]\left[\mathrm{C}_{3} \mathrm{C}_{1} \mathrm{im}\right][\mathrm{Tos}],[\mathrm{Si}]\left[\mathrm{C}_{3} \mathrm{C}_{1} \mathrm{im}\right][\mathrm{Male}]$ and $[\mathrm{Si}]\left[\mathrm{C}_{3} \mathrm{C}_{1} \mathrm{im}\right]\left[\mathrm{NTf}_{2}\right]$.

Atom content (weight fraction percentage $\pm \sigma$ )

\begin{tabular}{llll}
\hline $\mathbf{C}$ & $\mathbf{H}$ & $\mathbf{N}$ & $\mathbf{S}$
\end{tabular}

\begin{tabular}{|c|c|c|c|c|}
\hline Activated Silica & --- & $1.10 \pm 0.15$ & --- & --- \\
\hline$[\mathrm{Si}]\left[\mathrm{C}_{3}\right] \mathrm{Cl}$ & $5.90 \pm 0.16$ & $1.54 \pm 0.15$ & --- & --- \\
\hline$[\mathrm{Si}]\left[\mathrm{C}_{3} \mathrm{C}_{1} \mathrm{im}\right] \mathrm{Cl}$ & $8.58 \pm 0.11$ & $1.86 \pm 0.22$ & $2.33 \pm 0.12$ & --- \\
\hline$[\mathrm{Si}]\left[\mathrm{C}_{3} \mathrm{C}_{1} \mathrm{im}\right][\mathrm{SCN}]$ & $8.51 \pm 0.12$ & $1.99 \pm 0.05$ & $2.85 \pm 0.09$ & $0.88 \pm 0.08$ \\
\hline$[\mathrm{Si}]\left[\mathrm{C}_{3} \mathrm{C}_{1} \mathrm{im}\right]\left[\mathrm{N}(\mathrm{CN})_{2}\right]$ & $9.09 \pm 0.03$ & $2.16 \pm 0.15$ & $4.29 \pm 0.02$ & --- \\
\hline$[\mathrm{Si}]\left[\mathrm{C}_{3} \mathrm{C}_{1} \mathrm{im}\right][\mathrm{Tos}]$ & $10.62 \pm 0.01$ & $2.31 \pm 0.10$ & $2.32 \pm 0.02$ & $0.69 \pm 0.07$ \\
\hline$[\mathrm{Si}]\left[\mathrm{C}_{3} \mathrm{C}_{1} \mathrm{im}\right][\mathrm{Male}]$ & $11.12 \pm 0.07$ & $2.42 \pm 0.09$ & $2.27 \pm 0.10$ & --- \\
\hline$[\mathrm{Si}]\left[\mathrm{C}_{3} \mathrm{C}_{1} \mathrm{im}\right]\left[\mathrm{NTf}_{2}\right]$ & $9.18 \pm 0.03$ & $1.97 \pm 0.18$ & $2.88 \pm 0.10$ & $1.53 \pm 0.04$ \\
\hline
\end{tabular}

The carbon and nitrogen contents (in weight fraction percentage) of the supported materials range from $(8.51 \pm 0.11) \%$ to $(11.12 \pm 0.07) \%$ and from $(2.27 \pm 0.10) \%$ to $(4.29$ $\pm 0.02) \%$, respectively, depending on the carbon and nitrogen content of the anion. No nitrogen and carbon were detected in activated silica, supporting the absence of organic moieties in the starting material. Furthermore, sulphur was identified in $[\mathrm{Si}]\left[\mathrm{C}_{3} \mathrm{C}_{1} \mathrm{im}\right][\mathrm{SCN}],[\mathrm{Si}]\left[\mathrm{C}_{3} \mathrm{C}_{1} \mathrm{im}\right][\mathrm{Tos}]$ and $[\mathrm{Si}]\left[\mathrm{C}_{3} \mathrm{C}_{1} \mathrm{im}\right]\left[\mathrm{NTf}_{2}\right]$, ranging from $(0.69 \pm$ $0.07) \%$ to $(1.53 \pm 0.04) \%$. These results prove that the studied ILs were immobilized on the silica surface and that the anion exchange was carried out successfully. The functionalization degree, based on the elemental analysis results, correspond to an 
average of $65.4 \%$ of functionalized 1-methyl-3-propylimidazolium $\left(\left[\mathrm{C}_{1} \mathrm{C}_{3} \mathrm{im}\right]^{+}\right)$of the $[\mathrm{Si}]\left[\mathrm{C}_{3}\right] \mathrm{Cl}$ material, i.e. $65.4 \%$ of the available methyl terminal sites of $[\mathrm{Si}]\left[\mathrm{C}_{3}\right] \mathrm{Cl}$ reacted with $\mathrm{N}$-methylimidazole.

The specific surface area of silica, of $[\mathrm{Si}]\left[\mathrm{C}_{3}\right] \mathrm{Cl}$ and of the synthetized SILs were determined by nitrogen adsorption using the BET (Brunaver-Emmett-Teller) method (results given in Table 2). A decrease of the specific surface area of $[\mathrm{Si}]\left[\mathrm{C}_{3}\right] \mathrm{Cl}$ is observed when compared to the original silica and of SILs when compared with the respective precursor material $\left([\mathrm{Si}]\left[\mathrm{C}_{3}\right] \mathrm{Cl}\right)$. Silica has the highest value of pore diameter $(49.485 \AA)$, whereas $[\mathrm{Si}]\left[\mathrm{C}_{3}\right] \mathrm{Cl}$ has the lowest value $(38.746 \AA)$. The synthetized SILs show a pore diameter in the range between 42.227and $48.336 \AA$.

Table 2. BET surface area $\left(\mathrm{S}_{\mathrm{BET}}\right), \mathrm{BJH}$ pore surface area $(\mathrm{A}), \mathrm{BJH}$ pore volume $(\mathrm{V})$, pore size diameter $\left(\mathrm{D}_{\mathrm{p}}\right)$ and point zero charge (pzc) of silica, of $[\mathrm{Si}]\left[\mathrm{C}_{3}\right] \mathrm{Cl}$ and of SILs.

\begin{tabular}{|c|c|c|c|c|c|}
\hline & $\begin{array}{c}\mathrm{S}_{\mathrm{BET}} \\
\left(\mathrm{m}^{2} / \mathrm{g}\right)\end{array}$ & $\begin{array}{c}\text { A } \\
\left(\mathrm{m}^{2} / \mathrm{g}\right)\end{array}$ & $\begin{array}{c}\mathrm{V} \\
\left(\mathrm{cm}^{3} / \mathrm{g}\right)\end{array}$ & $\begin{array}{l}\mathrm{D}_{\mathrm{p}} \\
(\AA)\end{array}$ & pzc \\
\hline Silica & 434.545 & 569.536 & 0.705 & 49.485 & 3.4 \\
\hline$[\mathrm{Si}]\left[\mathrm{C}_{3}\right] \mathrm{Cl}$ & 322.911 & 326.977 & 0.317 & 38.746 & 4.5 \\
\hline$[\mathrm{Si}]\left[\mathrm{C}_{3} \mathrm{C}_{1} \mathrm{im}\right] \mathrm{Cl}$ & 185.252 & 256.100 & 0.289 & 45.213 & 8.9 \\
\hline$[\mathrm{Si}]\left[\mathrm{C}_{3} \mathrm{C}_{1} \mathrm{im}\right][\mathrm{SCN}]$ & 292.154 & 340.016 & 0.360 & 42.386 & 7.7 \\
\hline$[\mathrm{Si}]\left[\mathrm{C}_{3} \mathrm{C}_{1} \mathrm{im}\right]\left[\mathrm{N}(\mathrm{CN})_{2}\right]$ & 283.799 & 346.698 & 0.372 & 42.939 & 9.6 \\
\hline$[\mathrm{Si}]\left[\mathrm{C}_{3} \mathrm{C}_{1} \mathrm{im}\right][\mathrm{Tos}]$ & 256.071 & 321.350 & 0.339 & 42.227 & 8.8 \\
\hline$[\mathrm{Si}]\left[\mathrm{C}_{3} \mathrm{C}_{1} \mathrm{im}\right][\mathrm{Male}]$ & 252.738 & 329.794 & 0.383 & 46.504 & 7.8 \\
\hline$[\mathrm{Si}]\left[\mathrm{C}_{3} \mathrm{C}_{1} \mathrm{im}\right]\left[\mathrm{NTf}_{2}\right]$ & 105.681 & 148.041 & 0.179 & 48.336 & 10.1 \\
\hline
\end{tabular}

The point zero charge (pzc) was determined for silica, $[\mathrm{Si}]\left[\mathrm{C}_{3}\right] \mathrm{Cl}$ and synthetized SILs, whose results are provided in Table 2. Silica has the lowest pzc value (3.4). After the 
reaction with 3-chloropropyltrimethoxysilane, the pzc increases to 4.5. The six SILs present a higher pzc value when compared with silica and the precursor material $\left([\mathrm{Si}]\left[\mathrm{C}_{3}\right] \mathrm{Cl}\right.$ ), ranging from 7.7 (obtained with $[\mathrm{Si}]\left[\mathrm{C}_{3} \mathrm{C}_{1} \mathrm{im}\right][\mathrm{SCN}]$ ) to 10.1 (obtained with $\left.[\mathrm{Si}]\left[\mathrm{C}_{3} \mathrm{C}_{1} \mathrm{im}\right]\left[\mathrm{NTf}_{2}\right]\right)$. These results indicate that the SILs surface is more positively charged when compared to the silica and the $[\mathrm{Si}]\left[\mathrm{C}_{3}\right] \mathrm{Cl}$ material. These data are in agreement with the chemical structures of silica and SILs, where imidazolium cations are present and exposed in the surface of the former.

\subsection{Adsorption kinetics, diffusion models and isotherms of sodium diclofenac in} SILs

The adsorption kinetic curves of sodium diclofenac in all SILs were determined in order to evaluate and set the appropriate contact time for the adsorption isotherms studies. The results obtained are depicted in Fig. 5, and in Tables SI3 to SI8 given in the Supplementary Material. The adsorption efficiency of sodium diclofenac on the six SILs is also shown in Fig. SI3 in the Supplementary Material. Under the conditions evaluated, there is a plateau in the equilibrium concentration of adsorbate in the solid phase $\left(q_{e}\right)$, reached after $15 \mathrm{~min}$ of equilibrium, and kept for at least $180 \mathrm{~min}$. Furthermore, for $[\mathrm{Si}]\left[\mathrm{C}_{3} \mathrm{C}_{1} \mathrm{im}\right] \mathrm{Cl}$, the maximum equilibrium concentration of adsorbate found in the solid phase was $0.310 \mathrm{mmol.g}{ }^{-1}$, corresponding to an adsorption efficiency of $(92.9 \pm 0.4) \%$. According to the obtained results, the equilibrium concentration of adsorbate, i.e. sodium diclofenac, in the solid phase decreases in the following sequence of SILs: $[\mathrm{Si}]\left[\mathrm{C}_{3} \mathrm{C}_{1} \mathrm{im}\right] \mathrm{Cl}>[\mathrm{Si}]\left[\mathrm{C}_{3} \mathrm{C}_{1} \mathrm{im}\right][\mathrm{SCN}]>[\mathrm{Si}]\left[\mathrm{C}_{3} \mathrm{C}_{1} \mathrm{im}\right]\left[\mathrm{N}(\mathrm{CN})_{2}\right]>[\mathrm{Si}]\left[\mathrm{C}_{3} \mathrm{C}_{1} \mathrm{im}\right][\mathrm{Tos}]>$ $[\mathrm{Si}]\left[\mathrm{C}_{3} \mathrm{C}_{1} \mathrm{im}\right][\mathrm{Male}]>[\mathrm{Si}]\left[\mathrm{C}_{3} \mathrm{C}_{1} \mathrm{im}\right]\left[\mathrm{NTf}_{2}\right]$. 


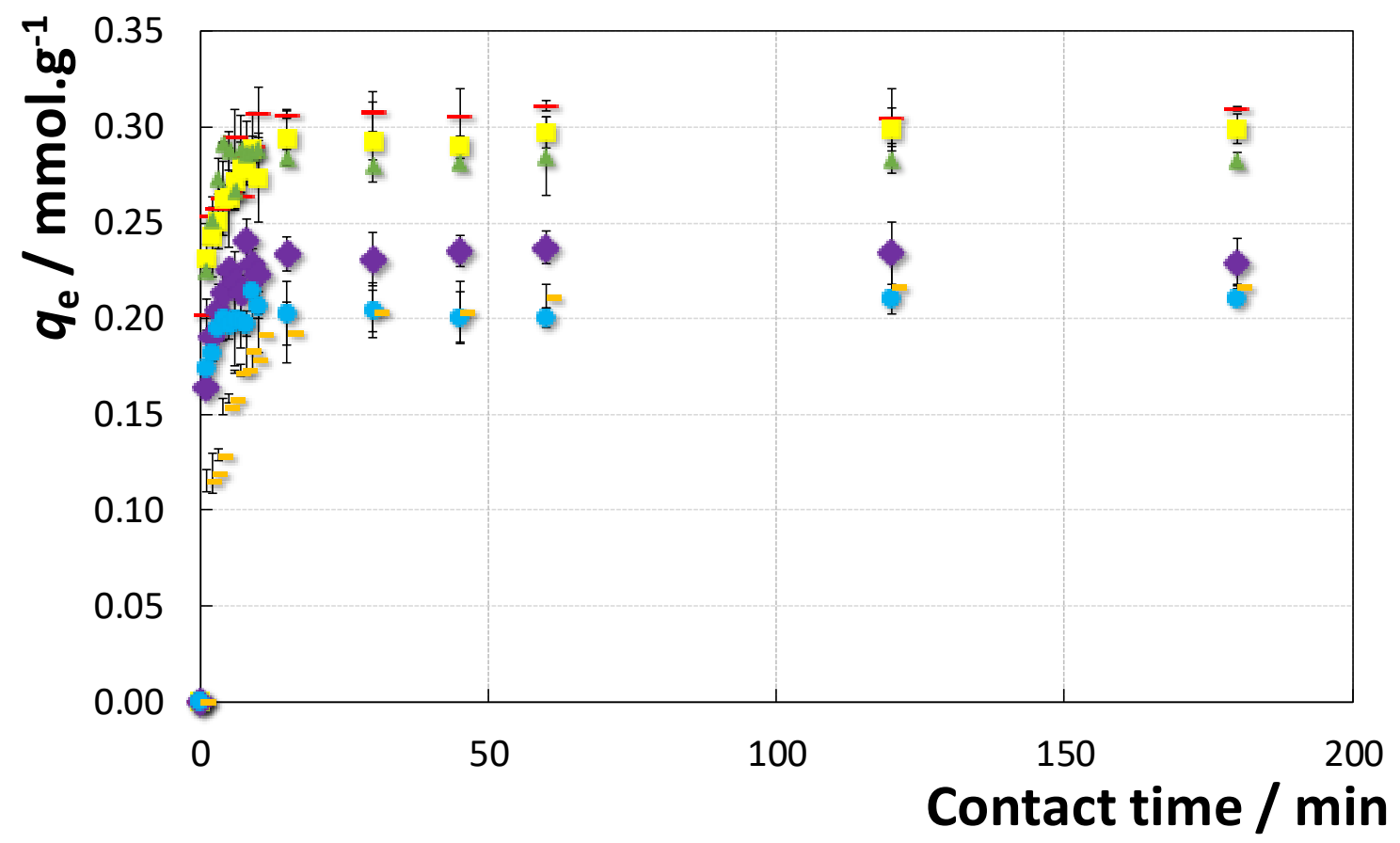

Fig. 5. Adsorption kinetic curves of sodium diclofenac in SILs at $298 \mathrm{~K}$ : $[\mathrm{Si}]\left[\mathrm{C}_{3} \mathrm{C}_{1} \mathrm{im}\right] \mathrm{Cl} ; \quad, \quad, \quad[\mathrm{Si}]\left[\mathrm{C}_{3} \mathrm{C}_{1} \mathrm{im}\right][\mathrm{SCN}] ; \quad \Delta, \quad[\mathrm{Si}]\left[\mathrm{C}_{3} \mathrm{C}_{1} \mathrm{im}\left[\mathrm{N}(\mathrm{CN})_{2}\right] ;\right.$ $[\mathrm{Si}]\left[\mathrm{C}_{3} \mathrm{C}_{1} \mathrm{im}\right][\mathrm{Tos}] ; \bigcirc,[\mathrm{Si}]\left[\mathrm{C}_{3} \mathrm{C}_{1} \mathrm{im}\right][\mathrm{Male}] ;$ and $=$, [Si] $\left[\mathrm{C}_{3} \mathrm{C}_{1} \mathrm{im}\right]\left[\mathrm{NTf}_{2}\right]$.

In order to study the adsorption mechanisms of sodium diclofenac in the prepared SILs, pseudo first-order kinetic (Eq. 2) and pseudo second-order (Eq. 3) kinetic models were used to correlate the experimental data. The adsorption kinetic parameters are summarized in Table 3, and the respective profiles shown in Fig. SI4 in the Supplementary Material. The correlation coefficients $\left(R^{2}\right)$ obtained for the first-order kinetic model range between 0.7245 and 0.8355 , while those obtained for the secondorder model are higher than 0.9997 , meaning that the last model describes better the experimental adsorption data. These results suggest that the adsorption process is controlled at the solid-liquid interface in the adsorbent $[40,49]$. Similar results were reported for the adsorption kinetics of various pollutants onto different adsorbents, such as activated carbon and carbon nanotubes [50,51]. The adsorption process involves 
physical adsorption, where the removal of sodium diclofenac from aqueous solutions is due to non-covalent interactions occurring between the API and the SIL. Given the chemical structure of both the drug and material, $\pi-\pi$, H-bonding and dispersive forces should be responsible for the effective physical adsorption of sodium diclofenac at the SIL surface. No anion exchange is however occurring. This fact is justified by the higher removal efficiency displayed by the chloride-based material. If anion exchange occurred (chloride by diclofenac), $[\mathrm{Si}]\left[\mathrm{C}_{3} \mathrm{C}_{1} \mathrm{im}\right] \mathrm{Cl}$ would be the less efficient material due to the stronger imidazolium-chloride interactions [52]. The absence of anion exchange was also confirmed by the quantification of chloride anions at the aqueous solution after equilibrium, with no increases in the chloride content observed. These results thus confirm that there is no leaching of the IL anion. Furthermore, the imidazolium cation absorbs in the ultraviolet range at ca. $211 \mathrm{~nm}$. By the absorbance spectra recorded between 190-900 nm, used for the diclofenac quantification, no changes in the curves profile were observed, demonstrating that there is no leaching of the imidazolium cation. It should be noted that non-functionalized silica was also tested under the same conditions. Although with a higher specific surface area $\left(\mathrm{S}_{\mathrm{BET}}\right.$ of $\left.434.545 \mathrm{~m}^{2} / \mathrm{g}\right)$ and a similar pore size diameter, even for a longer time (up to 180 minutes), no adsorption of diclofenac was verified on silica, at least up to the detection limits of the analytical equipment used. 
Table 3. Parameters of the pseudo first-order and pseudo second-order kinetic models.

\begin{tabular}{|c|c|c|c|c|}
\hline & \multirow{2}{*}{$\begin{array}{c}q_{e, \exp } / \\
\text { mmol.g }\end{array}$} & \multicolumn{3}{|c|}{ Pseudo first-order model } \\
\hline & & $\begin{array}{c}q_{e, c a l} / \\
\text { mmol.g-1 }\end{array}$ & $k_{1} / \min ^{-1}$ & $R^{2}$ \\
\hline$[\mathrm{Si}]\left[\mathrm{C}_{3} \mathrm{C}_{1} \mathrm{im}\right] \mathrm{Cl}$ & 0.31 & $0.12 \pm 0.38$ & $0.26 \pm 0.05$ & 0.7453 \\
\hline$[\mathrm{Si}]\left[\mathrm{C}_{3} \mathrm{C}_{1} \mathrm{im}\right][\mathrm{SCN}]$ & 0.30 & $0.03 \pm 0.19$ & $0.04 \pm 0.01$ & 0.8355 \\
\hline$[\mathrm{Si}]\left[\mathrm{C}_{3} \mathrm{C}_{1} \mathrm{im}\right]\left[\mathrm{N}(\mathrm{CN})_{2}\right]$ & 0.29 & $0.06 \pm 0.48$ & $0.32 \pm 0.07$ & 0.7245 \\
\hline$[\mathrm{Si}]\left[\mathrm{C}_{3} \mathrm{C}_{1} \mathrm{im}\right][\mathrm{Tos}]$ & 0.24 & $0.06 \pm 0.19$ & $0.15 \pm 0.03$ & 0.8148 \\
\hline$[\mathrm{Si}]\left[\mathrm{C}_{3} \mathrm{C}_{1} \mathrm{im}\right][\mathrm{Male}]$ & 0.22 & $0.04 \pm 0.18$ & $0.15 \pm 0.03$ & 0.7578 \\
\hline \multirow[t]{3}{*}[\mathrm{Si}]{$\left[\mathrm{C}_{3} \mathrm{C}_{1} \mathrm{im}\right]\left[\mathrm{NTf}_{2}\right]$} & 0.22 & $0.08 \pm 0.12$ & $0.07 \pm 0.01$ & 0.8186 \\
\hline & & \multicolumn{3}{|c|}{ Pseudo second-order model } \\
\hline & mmol.g ${ }^{-1}$ & $\begin{array}{c}q_{e, c a l} / \\
\text { mmol.g-1 }\end{array}$ & $\begin{array}{c}k_{2} / \\
\text { g.mmol }^{-1} \cdot \mathrm{min}^{-1}\end{array}$ & $R^{2}$ \\
\hline$[\mathrm{Si}]\left[\mathrm{C}_{3} \mathrm{C}_{1} \mathrm{im}\right] \mathrm{Cl}$ & 0.31 & $0.31 \pm 0.01$ & $6.22 \pm 0.50$ & 0.9999 \\
\hline$[\mathrm{Si}]\left[\mathrm{C}_{3} \mathrm{C}_{1} \mathrm{im}\right][\mathrm{SCN}]$ & 0.30 & $0.30 \pm 0.00$ & $5.43 \pm 0.28$ & 0.9999 \\
\hline$[\mathrm{Si}]\left[\mathrm{C}_{3} \mathrm{C}_{1} \mathrm{im}\right]\left[\mathrm{N}(\mathrm{CN})_{2}\right]$ & 0.29 & $0.28 \pm 0.01$ & $118.6 \pm 1.2$ & 0.9999 \\
\hline$[\mathrm{Si}]\left[\mathrm{C}_{3} \mathrm{C}_{1} \mathrm{im}\right][\mathrm{Tos}]$ & 0.24 & $0.23 \pm 0.02$ & $72.7 \pm 1.0$ & 0.9998 \\
\hline$[\mathrm{Si}]\left[\mathrm{C}_{3} \mathrm{C}_{1} \mathrm{im}\right][\mathrm{Male}]$ & 0.22 & $0.21 \pm 0.02$ & $8.77 \pm 1.19$ & 0.9997 \\
\hline$[\mathrm{Si}]\left[\mathrm{C}_{3} \mathrm{C}_{1} \mathrm{im}\right]\left[\mathrm{NTf}_{2}\right]$ & 0.22 & $0.22 \pm 0.01$ & $2.51 \pm 0.75$ & 0.9999 \\
\hline
\end{tabular}

The Boyd's film diffusion and Webber's pore diffusion models (Eqs. 4-6) were used to disclose the rate controlling step affecting the sorption process. The numerical results of the piecewise linear regression (PLR) applied to the experimental kinetic data obtained with the synthetized SILs are presented in Table 4. The intercept of the first linear segment in the Boyd's plot is 0.503 and 0.113 for $[\mathrm{Si}]\left[\mathrm{C}_{3} \mathrm{C}_{1} \mathrm{im}\right][\mathrm{SCN}]$ and $[\mathrm{Si}]\left[\mathrm{C}_{3} \mathrm{C}_{1} \mathrm{im}\right]\left[\mathrm{NTf}_{2}\right]$, respectively. These values of intercept are significantly different from zero, strongly suggesting that the film diffusion is the rate controlling mechanism 
during the first segment. On the other hand, the Boyd's plots for $[\mathrm{Si}]\left[\mathrm{C}_{3} \mathrm{C}_{1} \mathrm{im}\right] \mathrm{Cl}$, $[\mathrm{Si}]\left[\mathrm{C}_{3} \mathrm{C}_{1} \mathrm{im}\right]\left[\mathrm{N}(\mathrm{CN})_{2}\right],[\mathrm{Si}]\left[\mathrm{C}_{3} \mathrm{C}_{1} \mathrm{im}\right][\mathrm{Tos}]$ and $[\mathrm{Si}]\left[\mathrm{C}_{3} \mathrm{C}_{1} \mathrm{im}\right][\mathrm{Male}]$ present a first linear segment, whose confidence interval of the intercept (with 95\% confidence limits) includes zero. These results suggest that, under the investigated conditions, the film diffusion does not control the adsorption process during the initial period.

The numerical results for the Webber' plots obtained for the adsorption of sodium diclofenac onto SILs are presented in Table 4. Two operational stages were defined: the first stage corresponding to the steep-sloped portion of $q t$ vs $t^{1 / 2}$ plots and the second one resembling the linear gentle-sloped portion, with a breakpoint (square root of the time where the two linear segments intersects). These two stages may correspond to the diffusion of sodium diclofenac into the pores of different sizes, and gradually smaller, of the SILs [44]. The values of $\mathrm{k}_{\mathrm{id}}$ (given in Table 4) are in accordance with this assumption, i.e. higher $\mathrm{k}_{\mathrm{id}}$ values were recorded at the first stage. The higher $\mathrm{K}_{\mathrm{id}}$ value was obtained with $[\mathrm{Si}]\left[\mathrm{C}_{3} \mathrm{C}_{1} \mathrm{im}\right]\left[\mathrm{N}(\mathrm{CN})_{2}\right]$, indicating that the sodium diclofenac diffusion is faster in this SIL. 
Table 4. Results of piecewise linear regression for the first linear segment in the Boyd plots and of the first two linear segments in the Webber's plot for the sodium diclofenac adsorption onto SILs. The values given in parentheses correspond to the $95 \%$ confidence limits.

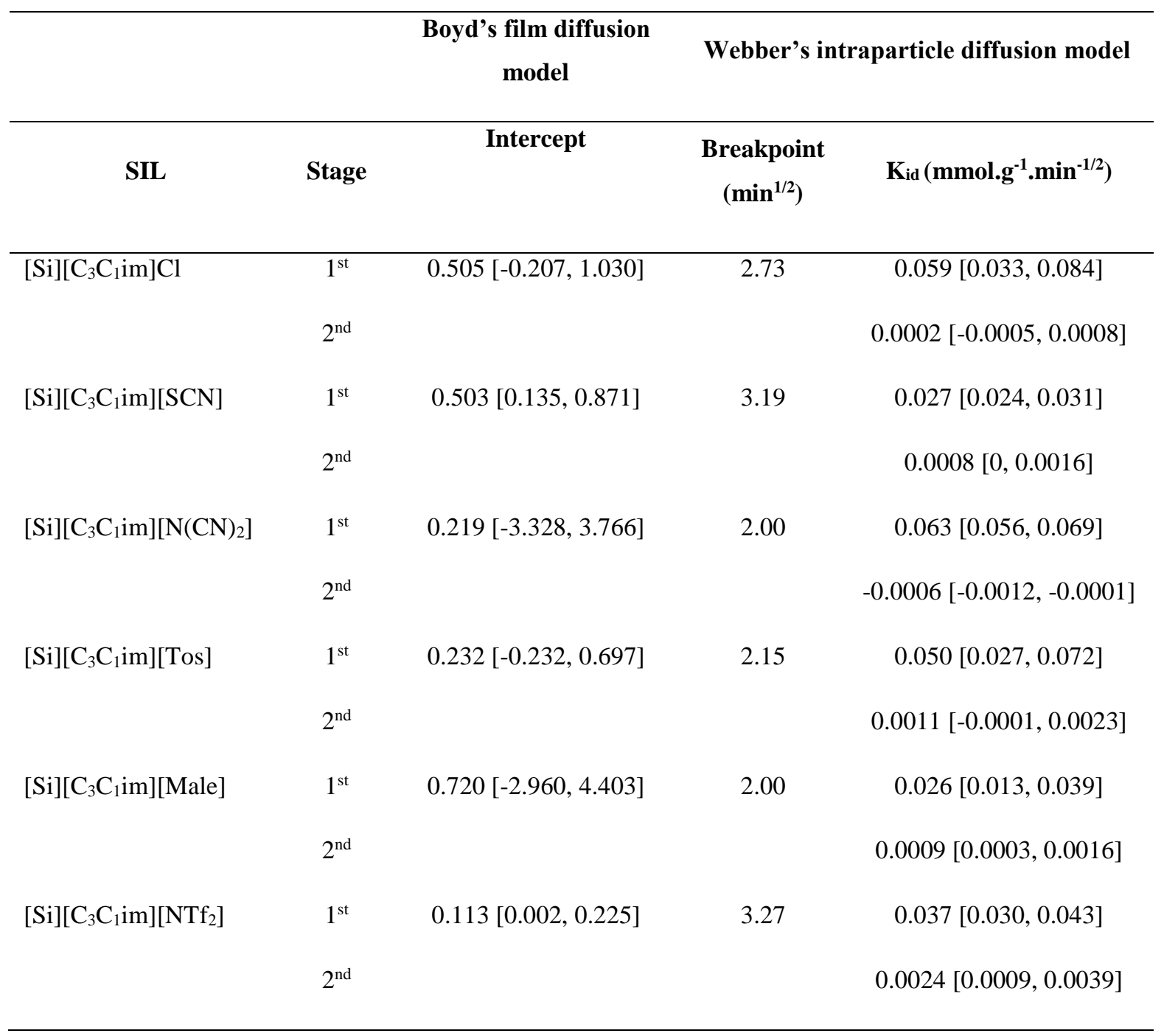

The experimental data on the adsorption isotherms at $298 \mathrm{~K}$ were fitted by the Langmuir [41] (Eq. 7) and the Freundlich [42] (Eq .8) models, using initial concentrations of sodium diclofenac ranging between 0.003 and $1.446 \mathrm{mmol} . \mathrm{L}^{-1}$. To guarantee that equilibrium was reached, the contact time to carry out the adsorption isotherms studies was set to $120 \mathrm{~min}$. The relationship between the equilibrium concentrations of sodium diclofenac between the solid and liquid phases is shown in Fig. 6 (the respective representations according to each SIL are given in Fig. SI5, and detailed data are given in Table SI9 in the 
Supplementary Material). The equilibrium adsorption of sodium diclofenac onto SILs increases with the increase of its initial concentration until saturation, where a plateau is reached at around $0.2 \mathrm{mmol} . \mathrm{L}^{-1}$ of an equilibrium concentration of adsorbate.

Table 5 provides the isotherms parameters and the correlation coefficients $\left(R^{2}\right)$ derived from Eqs. 4 and 5. Detailed data are given in Table SI9 in the Supplementary Material. The Langmuir and Freundlich models describe well the adsorption process, with correlation coefficients above 0.95 . However, adsorption data of sodium diclofenac onto $[\mathrm{Si}]\left[\mathrm{C}_{3} \mathrm{C}_{1} \mathrm{im}\right] \mathrm{Cl},[\mathrm{Si}]\left[\mathrm{C}_{3} \mathrm{C}_{1} \mathrm{im}\right][\mathrm{SCN}],[\mathrm{Si}]\left[\mathrm{C}_{3} \mathrm{C}_{1} \mathrm{im}\right]\left[\mathrm{N}(\mathrm{CN})_{2}\right]$ and $[\mathrm{Si}]\left[\mathrm{C}_{3} \mathrm{C}_{1} \mathrm{im}\right][\mathrm{Tos}]$ fit better to the Langmuir model $\left(R^{2}=0.9514,0.9710,0.9650\right.$ and 0.9558 , respectively), while for the SILs $[\mathrm{Si}]\left[\mathrm{C}_{3} \mathrm{C}_{1} \mathrm{im}\right][\mathrm{Male}]$ and $[\mathrm{Si}]\left[\mathrm{C}_{3} \mathrm{C}_{1} \mathrm{im}\right]\left[\mathrm{NTf}_{2}\right]$ the Freundlich model $\left(R^{2}\right.$ $=0.9615$ and 0.9898 , respectively) better describes the adsorption isotherms of sodium diclofenac. This trend suggests that the adsorption of the drug onto $[\mathrm{Si}]\left[\mathrm{C}_{3} \mathrm{C}_{1} \mathrm{im}\right] \mathrm{Cl}$, $[\mathrm{Si}]\left[\mathrm{C}_{3} \mathrm{C}_{1} \mathrm{im}\right][\mathrm{SCN}],[\mathrm{Si}]\left[\mathrm{C}_{3} \mathrm{C}_{1} \mathrm{im}\right]\left[\mathrm{N}(\mathrm{CN})_{2}\right]$ and $[\mathrm{Si}]\left[\mathrm{C}_{3} \mathrm{C}_{1} \mathrm{im}\right][\mathrm{Tos}]$ occurs through the formation of a monolayer adsorbate on the outer surface of the adsorbent, where no further adsorption takes place. On the other hand, the adsorption of sodium diclofenac onto $[\mathrm{Si}]\left[\mathrm{C}_{3} \mathrm{C}_{1} \mathrm{im}\right][\mathrm{Male}]$ and $[\mathrm{Si}]\left[\mathrm{C}_{3} \mathrm{C}_{1} \mathrm{im}\right]\left[\mathrm{NTf}_{2}\right]$ corresponds to an adsorption behaviour on both homogeneous and heterogeneous surfaces, where an adsorption process followed by a pore filling mechanism might occur. Therefore, different ionic structures as counter ions in the supported material seem to lead to different adsorption processes. 

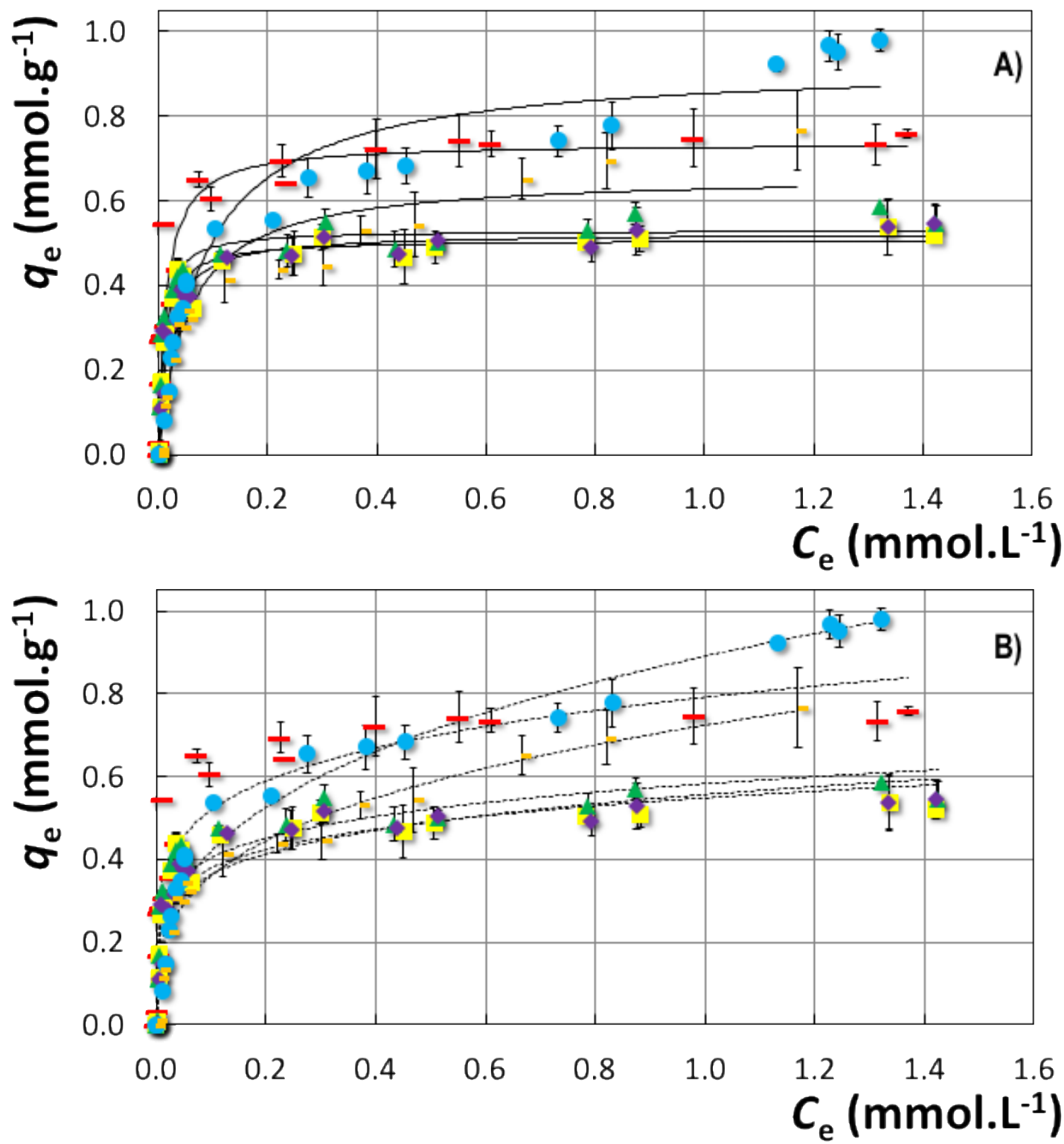

Fig. 6. Adsorption isotherms of sodium diclofenac onto SILs at $298 \mathrm{~K}$ : A) Langmuir fitting (Eq. 5); and B) Freundlich fitting (Eq. 6); for -, $[\mathrm{Si}]\left[\mathrm{C}_{3} \mathrm{C}_{1} \mathrm{im}\right] \mathrm{Cl}$; , $[\mathrm{Si}]\left[\mathrm{C}_{3} \mathrm{C}_{1} \mathrm{im}\right][\mathrm{SCN}] ; \quad \Delta, \quad[\mathrm{Si}]\left[\mathrm{C}_{3} \mathrm{C}_{1} \mathrm{im}\left[\mathrm{N}(\mathrm{CN})_{2}\right] ; \quad \diamond, \quad[\mathrm{Si}]\left[\mathrm{C}_{3} \mathrm{C}_{1} \mathrm{im}\right][\mathrm{Tos}]\right.$ $[\mathrm{Si}]\left[\mathrm{C}_{3} \mathrm{C}_{1} \mathrm{im}\right][\mathrm{Male}] ;$ and $",[\mathrm{Si}]\left[\mathrm{C}_{3} \mathrm{C}_{1} \mathrm{im}\right]\left[\mathrm{NTf}_{2}\right]$. 
Table 5. Parameters and correlation coefficients obtained with the Langmuir and Freundlich models regarding the adsorption isotherms of sodium diclofenac onto the six SILs.

\section{Langmuir model}

\begin{tabular}{lccc}
\hline \multicolumn{1}{c}{ SIL } & $\left(\boldsymbol{q}_{\max } \pm \boldsymbol{\sigma}\right) / \mathbf{~ m m o l . g}^{-1}$ & $(\boldsymbol{B} \pm \boldsymbol{\sigma}) / \mathbf{L} . \mathbf{m m o l}$ & $\boldsymbol{R}^{\mathbf{2}}$ \\
\hline$[\mathrm{Si}]\left[\mathrm{C}_{3} \mathrm{C}_{1} \mathrm{im}\right] \mathrm{Cl}$ & $0.74 \pm 0.03$ & $68.99 \pm 1.29$ & 0.9514 \\
{$[\mathrm{Si}]\left[\mathrm{C}_{3} \mathrm{C}_{1} \mathrm{im}\right][\mathrm{SCN}]$} & $0.51 \pm 0.03$ & $92.73 \pm 6.62$ & 0.9710 \\
{$[\mathrm{Si}]\left[\mathrm{C}_{3} \mathrm{C}_{1} \mathrm{im}\right]\left[\mathrm{N}(\mathrm{CN})_{2}\right]$} & $0.53 \pm 0.04$ & $120.55 \pm 7.16$ & 0.9650 \\
{$[\mathrm{Si}]\left[\mathrm{C}_{3} \mathrm{C}_{1} \mathrm{im}\right][\mathrm{Tos}]$} & $0.52 \pm 0.02$ & $56.68 \pm 4.54$ & 0.9558 \\
{$[\mathrm{Si}]\left[\mathrm{C}_{3} \mathrm{C}_{1} \mathrm{im}\right][\mathrm{Male}]$} & $0.92 \pm 0.03$ & $12.16 \pm 1.82$ & 0.9553 \\
{$[\mathrm{Si}]\left[\mathrm{C}_{3} \mathrm{C}_{1} \mathrm{im}\right]\left[\mathrm{NTf}_{2}\right]$} & $0.66 \pm 0.07$ & $18.64 \pm 4.13$ & 0.9223
\end{tabular}

Freundlich model

\begin{tabular}{lccc}
\hline \multicolumn{1}{c}{ SIL } & $\left(\boldsymbol{K}_{\boldsymbol{f}} \mathbf{\pm} \boldsymbol{\sigma}\right) / \mathbf{~ m m o l . g}^{-1}$ & $(\boldsymbol{n} \pm \boldsymbol{\sigma})$ & $\mathbf{R}^{\mathbf{2}}$ \\
\hline$[\mathrm{Si}]\left[\mathrm{C}_{3} \mathrm{C}_{1} \mathrm{im}\right] \mathrm{Cl}$ & $0.79 \pm 0.04$ & $5.46 \pm 0.03$ & 0.8409 \\
{$[\mathrm{Si}]\left[\mathrm{C}_{3} \mathrm{C}_{1} \mathrm{im}\right][\mathrm{SCN}]$} & $0.55 \pm 0.03$ & $6.23 \pm 0.03$ & 0.8404 \\
{$[\mathrm{Si}]\left[\mathrm{C}_{3} \mathrm{C}_{1} \mathrm{im}\right]\left[\mathrm{N}(\mathrm{CN})_{2}\right]$} & $0.58 \pm 0.03$ & $6.29 \pm 0.02$ & 0.8603 \\
{$[\mathrm{Si}]\left[\mathrm{C}_{3} \mathrm{C}_{1} \mathrm{im}\right][\mathrm{Tos}]$} & $0.56 \pm 0.03$ & $5.43 \pm 0.03$ & 0.8511 \\
{$[\mathrm{Si}]\left[\mathrm{C}_{3} \mathrm{C}_{1} \mathrm{im}\right][\mathrm{Male}]$} & $0.89 \pm 0.02$ & $3.03 \pm 0.03$ & 0.9615 \\
{$[\mathrm{Si}]\left[\mathrm{C}_{3} \mathrm{C}_{1} \mathrm{im}\right]\left[\mathrm{NTf}_{2}\right]$} & $0.72 \pm 0.02$ & $3.32 \pm 0.03$ & 0.9898
\end{tabular}

According to the best fitting corresponding to each SIL, concentrations of adsorbate in the solid phase $\left(q_{e}\right)$ of $(0.74 \pm 0.03),(0.51 \pm 0.03),(0.53 \pm 0.04)$, and $(0.52 \pm 0.02)$ mmol.g ${ }^{-1}$ were obtained for $[\mathrm{Si}]\left[\mathrm{C}_{3} \mathrm{C}_{1} \mathrm{im}\right] \mathrm{Cl},[\mathrm{Si}]\left[\mathrm{C}_{3} \mathrm{C}_{1} \mathrm{im}\right][\mathrm{SCN}],[\mathrm{Si}]\left[\mathrm{C}_{3} \mathrm{C}_{1} \mathrm{im}\right]\left[\mathrm{N}(\mathrm{CN})_{2}\right]$, and $[\mathrm{Si}]\left[\mathrm{C}_{3} \mathrm{C}_{1} \mathrm{im}\right][\mathrm{Tos}]$, respectively. The best identified material is $\left[\mathrm{Si}_{[}\right]\left[\mathrm{C}_{3} \mathrm{C}_{1} \mathrm{im}\right] \mathrm{Cl}$, which can be seen as an advantage since this SIL is the one that requires less steps for preparation, contributing to the development of more sustainable technologies. These results suggest that IL anions with a higher hydrogen bond basicity, as chloride among 
the anions studied, display a better performance to adsorb sodium diclofenac. Although other anions such as acetate or dimethylphosphate can be used due to their high hydrogen bond basicity, we kept the material with chloride as the best option taking into account the material cost, stability and environmental compatibility issues. Furthermore, the preparation of $[\mathrm{Si}]\left[\mathrm{C}_{3} \mathrm{C}_{1} \mathrm{im}\right] \mathrm{Cl}$ requires one less step than the remaining materials with different anions.

According to the literature $[16,53,54]$, the maximum adsorption capacities of several materials for sodium diclofenac, as determined by the Langmuir equation, were found to be $0.24 \mathrm{mmol} . \mathrm{g}^{-1}$ for grape baggage [54], $0.08 \mathrm{mmol} . \mathrm{g}^{-1}$ for carbon nanotubes and 0.24 mmol. $\mathrm{g}^{-1}$ for commercial activated carbon [16]. Therefore, the maximum adsorption capacity for sodium diclofenac using $[\mathrm{Si}]\left[\mathrm{C}_{3} \mathrm{C}_{1} \mathrm{im}\right] \mathrm{Cl}\left(0.7 \mathrm{mmol} . \mathrm{g}^{-1}\right)$ presented in the current work is competitive to that afforded by activated carbon [16]. Moreover, since silica gel is a low-cost, inert and environmentally friendly material, and no high temperature pyrolysis steps are required, this strategy might be seen as more attractive from an environmental point of view for sodium diclofenac and other APIs adsorption/removal from aqueous media.

Although a high performance in the removal of sodium diclofenac is shown for $[\mathrm{Si}]\left[\mathrm{C}_{3} \mathrm{C}_{1} \mathrm{im}\right] \mathrm{Cl}$, from a sustainable perspective, these materials should be able to be regenerated and reused. Accordingly, after saturation of the $[\mathrm{Si}]\left[\mathrm{C}_{3} \mathrm{C}_{1} \mathrm{im}\right] \mathrm{Cl}$ with sodium diclofenac, we evaluated the drug desorption using several solvents, namely water, methanol, ethanol, 1-butanol, 1-butanol:water mixtures (85:15, v:v), 2-butanol, and 2butanol:water mixtures $(85: 15, \mathrm{v}: \mathrm{v})$. These solvents were chosen aiming at identifying promising and less toxic solvents in the desorption step than those commonly used [20]. Methanol was mainly studied to evaluate the molecular structure influence of alcohols for on the sodium diclofenac desorption. Detailed data are given in Table SI10 in the 
Supplementary Material. As expected, water has a low performance (ca. 10\%) to remove sodium diclofenac from the material. Methanol, ethanol, 1-butanol and 2-butanol lead to desorption values ranging from 24.7 to $33.0 \%$. However, mixtures of alcohols and water perform better than the isolated compounds due to a co-solvency effect, with the mixture composed of 1-butanol and water (85:15, v:v) leading to a removal of $(61.2 \pm 8.7) \%$ of the adsorbed sodium diclofenac.

After the sodium diclofenac desorption, the regeneration and reusability of the $[\mathrm{Si}]\left[\mathrm{C}_{3} \mathrm{C}_{1} \mathrm{im}\right] \mathrm{Cl}$ was investigated. The mixture composed of 1-butanol and water $(85: 15$, $\mathrm{v}: \mathrm{v})$ was used as the desorption solvent in 3 consecutive recycling steps of the material. The results obtained are depicted in Fig. 7. In the 4 cycles of sodium diclofenac adsorption, the adsorption efficiency of the material decreases as follows: $100>92.5>$ $86.3>75.0 \%$. Although the adsorption performance decreases along the regeneration steps, it should be remarked that after the third regeneration the material still keeps $75 \%$ of its initial adsorption efficiency for sodium diclofenac, and at a concentration of ca. 4 mmol.L $\mathrm{L}^{-1}$ which is well above the concentrations of the drug found in the real water samples aimed to be treated $-c f$. discussion below. 


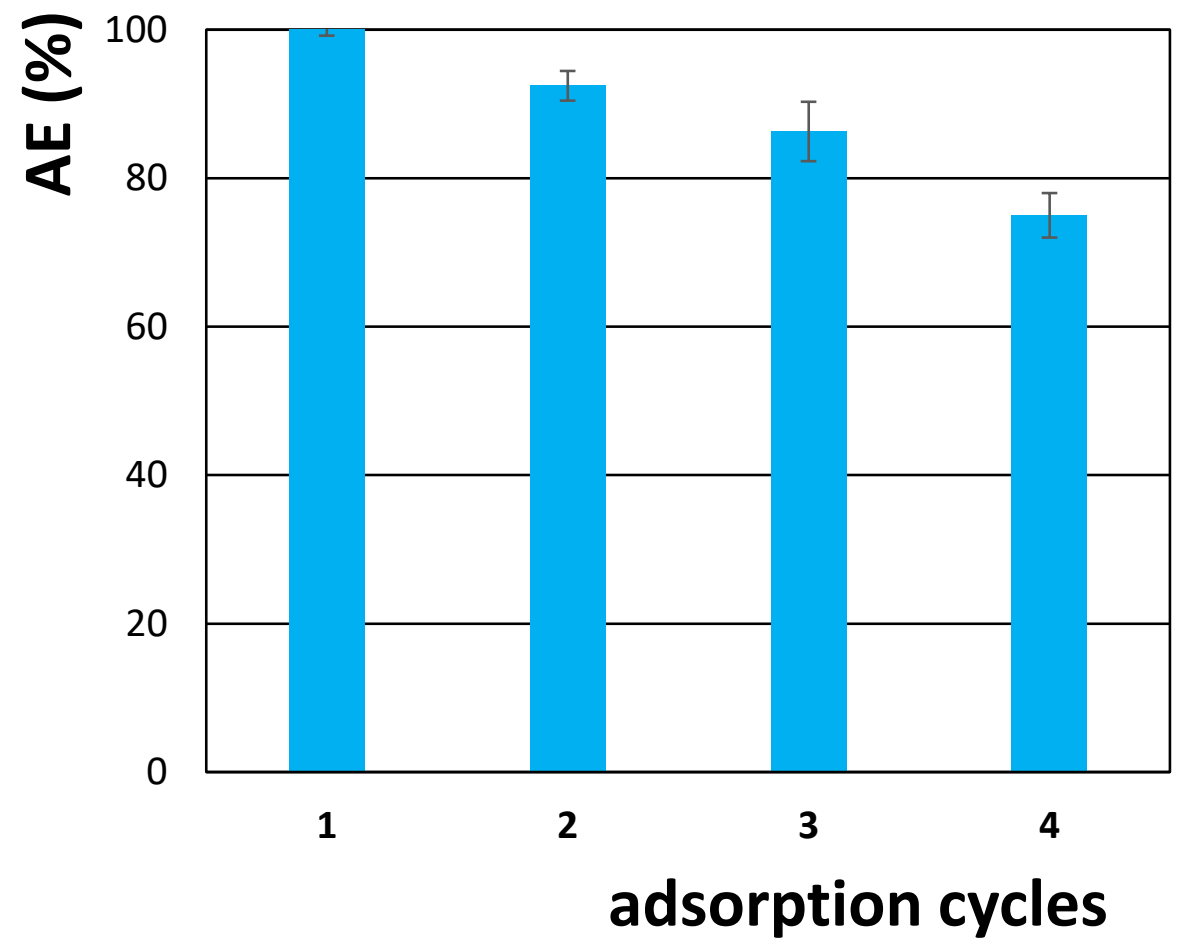

Fig. 7. Adsorption efficiency of sodium diclofenac onto $[\mathrm{Si}]\left[\mathrm{C}_{3} \mathrm{C}_{1} \mathrm{im}\right] \mathrm{Cl}$ in consecutive adsorption/desorption cycles corresponding to the material recycling.

Overall, the studied SILs display maximum equilibrium concentrations ranging from 0.503 to $0.754 \mathrm{mmol}$ ( 0.16 to $0.24 \mathrm{~g}$ ) of sodium diclofenac adsorbed per gram of material. Diclofenac has been detected in effluents from WWTP/STP at levels ranging from 460 to $3300 \mathrm{ng} . \mathrm{L}^{-1}$ in Europe, from < 0.5 to $177 \mathrm{ng} . \mathrm{L}^{-1}$ in North America, and from 8.8 to 127 ng. $\mathrm{L}^{-1}$ in Asia and Australia [55]. Considering the largest reported value of $3300 \mathrm{ng} . \mathrm{L}^{-1}$, $1 \mathrm{~g}$ of $[\mathrm{Si}]\left[\mathrm{C}_{3} \mathrm{C}_{1} \mathrm{im}\right] \mathrm{Cl}$ is "ideally" able to treat around $50,000 \mathrm{~L}$ of water, a significantly higher volume than those reported using other strategies involving ionic liquids [56]. Furthermore, $[\mathrm{Si}]\left[\mathrm{C}_{3} \mathrm{C}_{1} \mathrm{im}\right] \mathrm{Cl}$ can be regenerated for at least 3 times while keeping $75 \%$ of its initial adsorption capacity. Therefore, adequate SILs can be envisioned as efficient filters to be implemented at domestic environment in countries where the levels of pharmaceuticals are particularly high in drinking water. 


\section{Conclusions}

Six supported IL-based silica materials were synthesized and characterized, and further evaluated as adsorption materials to remove NSAIDs/APIs from aqueous media. The adsorption kinetics, isotherms and diffusion models of sodium diclofenac, as a major representative of the NSAIDs class, were determined for all materials. The film diffusion is the rate controlling mechanism for the adsorption of sodium diclofenac onto $[\mathrm{Si}]\left[\mathrm{C}_{3} \mathrm{C}_{1} \mathrm{im}\right][\mathrm{SCN}]$ and $[\mathrm{Si}]\left[\mathrm{C}_{3} \mathrm{C}_{1} \mathrm{im}\right]\left[\mathrm{NTf}_{2}\right]$, but does not control the process during the initial period for $[\mathrm{Si}]\left[\mathrm{C}_{3} \mathrm{C}_{1} \mathrm{im}\right] \mathrm{Cl}, \quad[\mathrm{Si}]\left[\mathrm{C}_{3} \mathrm{C}_{1} \mathrm{im}\right]\left[\mathrm{N}(\mathrm{CN})_{2}\right], \quad[\mathrm{Si}]\left[\mathrm{C}_{3} \mathrm{C}_{1} \mathrm{im}\right][\mathrm{Tos}]$ and $[\mathrm{Si}]\left[\mathrm{C}_{3} \mathrm{C}_{1} \mathrm{im}\right][\mathrm{Male}]$. The adsorption data fit well with the Langmuir model for $[\mathrm{Si}]\left[\mathrm{C}_{3} \mathrm{C}_{1} \mathrm{im}\right] \mathrm{Cl},[\mathrm{Si}]\left[\mathrm{C}_{3} \mathrm{C}_{1} \mathrm{im}\right][\mathrm{SCN}],[\mathrm{Si}]\left[\mathrm{C}_{3} \mathrm{C}_{1} \mathrm{im}\right]\left[\mathrm{N}(\mathrm{CN})_{2}\right]$ and $[\mathrm{Si}]\left[\mathrm{C}_{3} \mathrm{C}_{1} \mathrm{im}\right][\mathrm{Tos}]$, and with the Freundlich model for $[\mathrm{Si}]\left[\mathrm{C}_{3} \mathrm{C}_{1} \mathrm{im}\right][\mathrm{Male}]$ and $[\mathrm{Si}]\left[\mathrm{C}_{3} \mathrm{C}_{1} \mathrm{im}\right]\left[\mathrm{NTf}_{2}\right]$, and for which the adsorption kinetics in all materials is better described by a pseudo-second order model. A maximum equilibrium concentration of sodium diclofenac in the solid phase of $0.74 \mathrm{mmol}$ (or $0.235 \mathrm{~g}$ ) per $\mathrm{g}$ of SIL was obtained. The mixture composed of 1-butanol and water $(85: 15, \mathrm{v}: \mathrm{v})$ was identified as the most promising to remove diclofenac and to allow the material $[\mathrm{Si}]\left[\mathrm{C}_{3} \mathrm{C}_{1} \mathrm{im}\right] \mathrm{Cl}$ regeneration and reuse, at least for more 3 times while keeping $75 \%$ of its initial adsorption efficiency. Taking into account the maximum reported amount of diclofenac in WWTPs/STPs in Europe, $1 \mathrm{~g}$ of $[\mathrm{Si}]\left[\mathrm{C}_{3} \mathrm{C}_{1} \mathrm{im}\right] \mathrm{Cl}$ is able to "ideally" treat ca. 50,000 L of water. This material can thus be envisioned to be applied at domestic environments to treat drinking water.

\section{Acknowledgements}

This work was developed within the scope of the project CICECO-Aveiro Institute of Materials, FCT Ref. UID/CTM/50011/2019, financed by national funds through the FCT/MCTES. H.F.D. Almeida acknowledges FCT for the PhD grant 
SFRH/BD/88369/2012. M.C.N. acknowledges University of Aveiro for funding in the scope of the framework contract foreseen in the numbers 4,5 and 6 of the article 23 , of the Decree-Law 57/2016, of August 29, changed by Law 57/2017, of July 19. This work was financially supported by the project POCI-01-0145-FEDER-031106 (IonCytDevice) funded by FEDER, through COMPETE2020 - Programa Operacional Competitividade e Internacionalização (POCI), and by national funds (OE), through FCT/MCTES, and developed in the scope of the "Smart Green Homes" Project [POCI-01-0247-FEDER007678], a co-promotion between Bosch Termotecnologia S.A. and the University of Aveiro. It is financed by Portugal 2020 under the Competitiveness an Internationalization Operational Program, and by the European Regional Development Fund. 


\section{References}

[1] T. aus der Beek, F.A. Weber, A. Bergmann, S. Hickmann, I. Ebert, A. Hein, A. Küster, Pharmaceuticals in the environment-Global occurrences and perspectives, Environ. Toxicol. Chem. 35 (2016) 823-835. doi:10.1002/etc.3339.

[2] K. Kummerer, Drugs in the environment: emission of drugs, diagnostic aids and disinfectants into wastewater by hospitals in relation to other sources - a review., Chemosphere. 45 (2001) 957-969. doi:10.1016/S0045-6535(01)00144-8.

[3] B. Halling-Sorensen, S. Nors Nielsen, P.K. Lanzky, F. Ingerslev, H.. Holten Lützhoft, S.E. Jorgensen, Occurrence, fate and effects of pharmaceutical substances in the environment- A review, Chemosphere. 36 (1998) 357-393. doi:10.1016/j.jhazmat.2012.10.020.

[4] J. Wang, B. He, D. Yan, X. Hu, Implementing ecopharmacovigilance (EPV) from a pharmacy perspective: A focus on non-steroidal anti-inflammatory drugs, Sci. Total Environ. 603-604 (2017) 772-784. doi:10.1016/j.scitotenv.2017.02.209.

[5] K. Fent, A.A. Weston, D. Caminada, Ecotoxicology of human pharmaceuticals, Aquat. Toxicol. 76 (2006) 122-159. doi:10.1016/j.aquatox.2005.09.009.

[6] R. Salgado, J.P. Noronha, A. Oehmen, G. Carvalho, M.A.M. Reis, Analysis of 65 pharmaceuticals and personal care products in 5 wastewater treatment plants in Portugal using a simplified analytical methodology, Water Sci. Technol. 62 (2010) 2862-2871. doi:10.2166/wst.2010.985.

[7] M.F. Rahman, E.K. Yanful, S.Y. Jasim, Endocrine disrupting compounds (EDCs) and pharmaceuticals and personal care products (PPCPs) in the aquatic environment: Implications for the drinking water industry and global environmental health, J. Water Health. 7 (2009) 224-243. doi:10.2166/wh.2009.021. 
[8] B. Kasprzyk-Hordern, R.M. Dinsdale, A.J. Guwy, The removal of pharmaceuticals, personal care products, endocrine disruptors and illicit drugs during wastewater treatment and its impact on the quality of receiving waters, Water Res. 43 (2009) 363-380. doi:10.1016/j.watres.2008.10.047.

[9] T. Heberer, Occurrence, fate, and removal of pharmaceutical residues in the aquatic environment: a review of recent research data Thomas, Toxicol. Lett. 131 (2002) 5-17. doi:10.1111/j.1439-0388.1936.tb00094.x.

[10] R. Rodil, J.B. Quintana, E. Concha-Graña, P. López-Mahía, S. MuniateguiLorenzo, D. Prada-Rodríguez, Emerging pollutants in sewage, surface and drinking water in Galicia (NW Spain), Chemosphere. 86 (2012) 1040-1049. doi:10.1016/j.chemosphere.2011.11.053.

[11] Pharmaceuticals and Personal Care Products in Water Cycle: An international review, 2004. http://www.wrc.org.za/wp-content/uploads/mdocs/GWRC PhAC International Review.pdf.

[12] L. Lonappan, S.K. Brar, R.K. Das, M. Verma, R.Y. Surampalli, Diclofenac and its transformation products: Environmental occurrence and toxicity - A review, Environ. Int. 96 (2016) 127-138. doi:10.1016/j.envint.2016.09.014.

[13] D. Fatta-Kassinos, E. Hapeshi, A. Achilleos, S. Meric, M. Gros, M. Petrovic, D. Barcelo, Existence of pharmaceutical compounds in tertiary treated urban wastewater that is utilized for reuse applications, Water Resour. Manag. 25 (2011) 1183-1193. doi:10.1007/s11269-010-9646-4.

[14] S. Zorita, L. Martensson, L. Mathiasson, Occurance and removal of pharmaceuticals in municipal sewage treatment system in the south of Sweden, Sci. Total Environ. 407 (2009) 2760-2770. doi:10.1016/j.scitotenv.2008.12.030.

[15] M. Gros, M. Petrović, A. Ginebreda, D. Barceló, Removal of pharmaceuticals 
during wastewater treatment and environmental risk assessment using hazard indexes, Environ. Int. 36 (2010) 15-26. doi:10.1016/j.envint.2009.09.002.

[16] Z. Hasan, N.A. Khan, S.H. Jhung, Adsorptive removal of diclofenac sodium from water with Zr-based metal-organic frameworks, Chem. Eng. J. 284 (2016) 14061413. doi:10.1016/j.cej.2015.08.087.

[17] B.N. Bhadra, I. Ahmed, S. Kim, S.H. Jhung, Adsorptive removal of ibuprofen and diclofenac from water using metal-organic framework-derived porous carbon, Chem. Eng. J. 314 (2017) 50-58. doi:10.1016/j.cej.2016.12.127.

[18] S. Zhuang, R. Cheng, J. Wang, Adsorption of diclofenac from aqueous solution using UiO-66-type metal-organic frameworks, Chem. Eng. J. 359 (2019) 354-362. doi:10.1016/j.cej.2018.11.150.

[19] B.N. Bhadra, P.W. Seo, S.H. Jhung, Adsorption of diclofenac sodium from water using oxidized activated carbon, Chem. Eng. J. 301 (2016) 27-34. doi:10.1016/j.cej.2016.04.143.

[20] H.J. An, B.N. Bhadra, N.A. Khan, S.H. Jhung, Adsorptive removal of wide range of pharmaceutical and personal care products from water by using metal azolate framework-6-derived porous carbon, Chem. Eng. J. 343 (2018) 447-454. doi:10.1016/j.cej.2018.03.025.

[21] N. Suriyanon, P. Punyapalakul, C. Ngamcharussrivichai, Mechanistic study of diclofenac and carbamazepine adsorption on functionalized silica-based porous materials, Chem. Eng. J. 214 (2013) 208-218. doi:10.1016/j.cej.2012.10.052.

[22] F.J. Beltrán, P. Pocostales, P. Alvarez, A. Oropesa, Diclofenac removal from water with ozone and activated carbon, J. Hazard. Mater. 163 (2009) 768-776. doi:10.1016/j.jhazmat.2008.07.033.

[23] M. Carballa, F. Omil, J.M. Lema, Removal of cosmetic ingredients and 
pharmaceuticals in sewage primary treatment, Water Res. 39 (2005) 4790-4796. doi:10.1016/j.watres.2005.09.018.

[24] Y. Zhang, S.U. Geißen, C. Gal, Carbamazepine and diclofenac: Removal in wastewater treatment plants and occurrence in water bodies, Chemosphere. 73 (2008) 1151-1161. doi:10.1016/j.chemosphere.2008.07.086.

[25] H. Qiu, S. Jiang, X. Liu, L. Zhao, Novel imidazolium stationary phase for highperformance liquid chromatography, J. Chromatogr. A. 1116 (2006) 46-50. doi:10.1016/j.chroma.2006.03.016.

[26] H. Qiu, S. Jiang, X. Liu, N-Methylimidazolium anion-exchange stationary phase for high-performance liquid chromatography, J. Chromatogr. A. 1103 (2006) 265270. doi:10.1016/j.chroma.2005.11.035.

[27] Q. Wang, G. a Baker, S.N. Baker, L. a Colón, Surface confined ionic liquid as a stationary phase for HPLC., Analyst. 131 (2006) 1000-1005. doi:10.1039/b607337a.

[28] G. V Myasoedova, N.P. Molochnikova, O.B. Mokhodoeva, B.F. Myasoedov, Application of ionic liquids for solid-phase extraction of trace elements., Anal. Sci. 24 (2008) 1351-3. doi:10.2116/analsci.24.1351.

[29] J. Li, Y. Cai, Y. Shi, S. Mou, G. Jiang, Analysis of phthalates via HPLC-UV in environmental water samples after concentration by solid-phase extraction using ionic liquid mixed hemimicelles, Talanta. 74 (2008) 498-504. doi:10.1016/j.talanta.2007.06.008.

[30] H. Yang, L. Bai, D. Wei, L. Yang, W. Wang, H. Chen, Y. Niu, Z. Xue, Ionic selfassembly of poly(ionic liquid)-polyoxometalate hybrids for selective adsorption of anionic dyes, Chem. Eng. J. 358 (2019) 850-859. doi:10.1016/j.cej.2018.10.100.

[31] M. Koel, Do we need green analytical chemistry?, Green Chem. 18 (2016) 923- 
931. doi:10.1039/c5gc02156a.

[32] S. Baj, A. Chrobok, S. Derfla, A new method for dialkyl peroxides synthesis in ionic liquids as solvents, Green Chem. 8 (2006) 292-295. doi:10.1039/b513863a.

[33] Q. Zhang, S. Zhang, Y. Deng, Recent advances in ionic liquid catalysis, Green Chem. 13 (2011) 2619-2637. doi:10.1039/c1gc15334j.

[34] C.L. Bentley, A.M. Bond, A.F. Hollenkamp, P.J. Mahon, J. Zhang, Electrochemistry of iodide, iodine, and iodine monochloride in chloride containing nonhaloaluminate ionic liquids, Anal. Chem. 88 (2016) 1915-1921. doi:10.1021/acs.analchem.5b04332.

[35] H. Passos, M.G. Freire, J. a. P. Coutinho, Ionic liquid solutions as extractive solvents for value-added compounds from biomass, Green Chem. (2014) 47864815. doi:10.1039/C4GC00236A.

[36] T. Welton, Ionic liquids in Green Chemistry, Green Chem. 13 (2011) 225. doi:10.1039/c0gc90047h.

[37] N. Fontanals, F. Borrull, R.M. Marcé, Ionic liquids in solid-phase extraction, TrAC - Trends Anal. Chem. 41 (2012) 15-26. doi:10.1016/j.trac.2012.08.010.

[38] P. De Voogt, M.L. Janex-Habibi, F. Sacher, L. Puijker, M. Mons, Development of a common priority list of pharmaceuticals relevant for the water cycle, Water Sci. Technol. 59 (2009) 39-46. doi:10.2166/wst.2009.764.

[39] S. Lagergren, Zur theorie der sogenannten adsorption geloster stoffe. Kungliga Svenska Vetenskapsakademiens, Handlingar. 24 (1898) 1-39.

[40] Y.S. Ho, G. McKay, Pseudo-second order model for sorption processes, Process Biochem. 34 (1999) 451-465. doi:10.1016/S0032-9592(98)00112-5.

[41] R.D. Harter, Curve-fit errors in Langmuir adsorption maxima., Soil Sci. Soc. Am. 48 (1984) 749-752. doi:10.2136/sssaj1984.03615995004800040010x. 
[42] C. Sheindorf, M. Rebhun, M. Sheintuch, A Freundlich-type multicomponent isotherm, J. Colloid Interface Sci. 79 (1981) 136-142. doi:10.1016/00219797(81)90056-4.

[43] Y.S. Ho, J.C.Y. Ng, G. McKay, Kinetics of pollutant sorption by biosorbents: Review, Sep. Purif. Methods. 29 (2000) 189-232. doi:10.1081/SPM-100100009.

[44] M.I. El-Khaiary, G.F. Malash, Common data analysis errors in batch adsorption studies, $\quad$ Hydrometallurgy. $\quad 105 \quad$ (2011) 314-320. doi:10.1016/j.hydromet.2010.11.005.

[45] G.F. Malash, M.I. El-Khaiary, Piecewise linear regression: A statistical method for the analysis of experimental adsorption data by the intraparticle-diffusion models, Chem. Eng. J. 163 (2010) 256-263. doi:10.1016/j.cej.2010.07.059.

[46] A.A. Saei, F. Jabbaribar, M.A.A. Fakhree, W.E. Acree, A. Jouyban, Solubility of sodium diclofenac in binary water + alcohol solvent mixtures at $25^{\circ} \mathrm{C}$, J. Drug Deliv. Sci. Technol. 18 (2008) 149-151. doi:10.1016/S1773-2247(08)50024-4.

[47] N. Fontanals, S. Ronka, F. Borrull, A.W. Trochimczuk, R.M. Marcé, Supported imidazolium ionic liquid phases: A new material for solid-phase extraction, Talanta. 80 (2009) 250-256. doi:10.1016/j.talanta.2009.06.068.

[48] P. Su, R. Wang, Y. Yu, Y. Yang, Microwave-assisted synthesis of ionic liquidmodified silica as a sorbent for the solid-phase extraction of phenolic compounds from water, Anal. Methods. 6 (2014) 704-709. doi:10.1039/C3AY41771A.

[49] J.P. Simonin, On the comparison of pseudo-first order and pseudo-second order rate laws in the modeling of adsorption kinetics, Chem. Eng. J. 300 (2016) 254263. doi:10.1016/j.cej.2016.04.079.

[50] E. Ayranci, O. Duman, Structural effects on the interactions of benzene and naphthalene sulfonates with activated carbon cloth during adsorption from aqueous 
solutions, Chem. Eng. J. 156 (2010) 70-76. doi:10.1016/j.cej.2009.09.038.

[51] O. Duman, C. Özcan, T. Gürkan Polat, S. Tunç, Carbon nanotube-based magnetic and non-magnetic adsorbents for the high-efficiency removal of diquat dibromide herbicide from water: OMWCNT, OMWCNT-Fe3O4 and OMWCNT-Kcarrageenan-Fe3O4 nanocomposites, Environ. Pollut. 244 (2019) 723-732. doi:10.1016/j.envpol.2018.10.071.

[52] A.M. Fernandes, M.A.A. Rocha, M.G. Freire, I.M. Marrucho, J.A.P. Coutinho, L.M.N.B.F. Santos, Evaluation of cation-anion interaction strength in ionic liquids, J. Phys. Chem. B. 115 (2011) 4033-4041. doi:10.1021/jp201084x.

[53] M. Antunes, V.I. Esteves, R. Guégan, J.S. Crespo, A.N. Fernandes, M. Giovanela, Removal of diclofenac sodium from aqueous solution by Isabel grape bagasse, Chem. Eng. J. 192 (2012) 114-121. doi:10.1016/j.cej.2012.03.062.

[54] S.K. Bajpai, M. Bhowmik, Adsorption of diclofenac sodium from aqueous solution using polyaniline as a potential sorbent. I. Kinetic studies, J. Appl. Polym. Sci. 117 (2010) 3615-3622. doi:10.1002/app.32263.

[55] M. Gavrilescu, K. Demnerová, J. Aamand, S. Agathos, F. Fava, Emerging pollutants in the environment: present and future challenges in biomonitoring, ecological risks and bioremediation, N. Biotechnol. 32 (2015) 147-156. doi:10.1016/j.nbt.2014.01.001.

[56] H.F.D. Almeida, I.M. Marrucho, M.G. Freire, Removal of nonsteroidal antiinflammatory drugs from aqueous environments with reusable ionic-liquid-based systems, ACS Sustain. Chem. Eng. 5 (2017) 2428-2436. doi:10.1021/acssuschemeng.6b02771. 